\title{
Integrating depression management into HIV care in Lilongwe, Malawi: Feasibility and impact
}

Brian Wells Pence

Michael Udedi

Kazione Kulisewa

Mina C. Hosseinipour

Steven M. Mphonda

See next page for additional authors

Follow this and additional works at: https://knowledgecommons.popcouncil.org/departments_sbsr-hiv

Part of the Public Health Commons

How does access to this work benefit you? Let us know!

\section{Recommended Citation}

Pence, Brian Wells, Michael Udedi, Kazione Kulisewa, Mina C. Hosseinipour, Steven M. Mphonda, Melissa A. Stockton, and Bradley N. Gaynes. 2021. "Integrating depression management into HIV care in Lilongwe, Malawi: Feasibility and impact," Project SOAR Final Report. Washington, DC: USAID I Project SOAR. 


\section{Authors}

Brian Wells Pence, Michael Udedi, Kazione Kulisewa, Mina C. Hosseinipour, Steven M. Mphonda, Melissa A. Stockton, and Bradley N. Gaynes 
Integrating Depression Management into HIV Care in Lilongwe, Malawi: Feasibility and impact

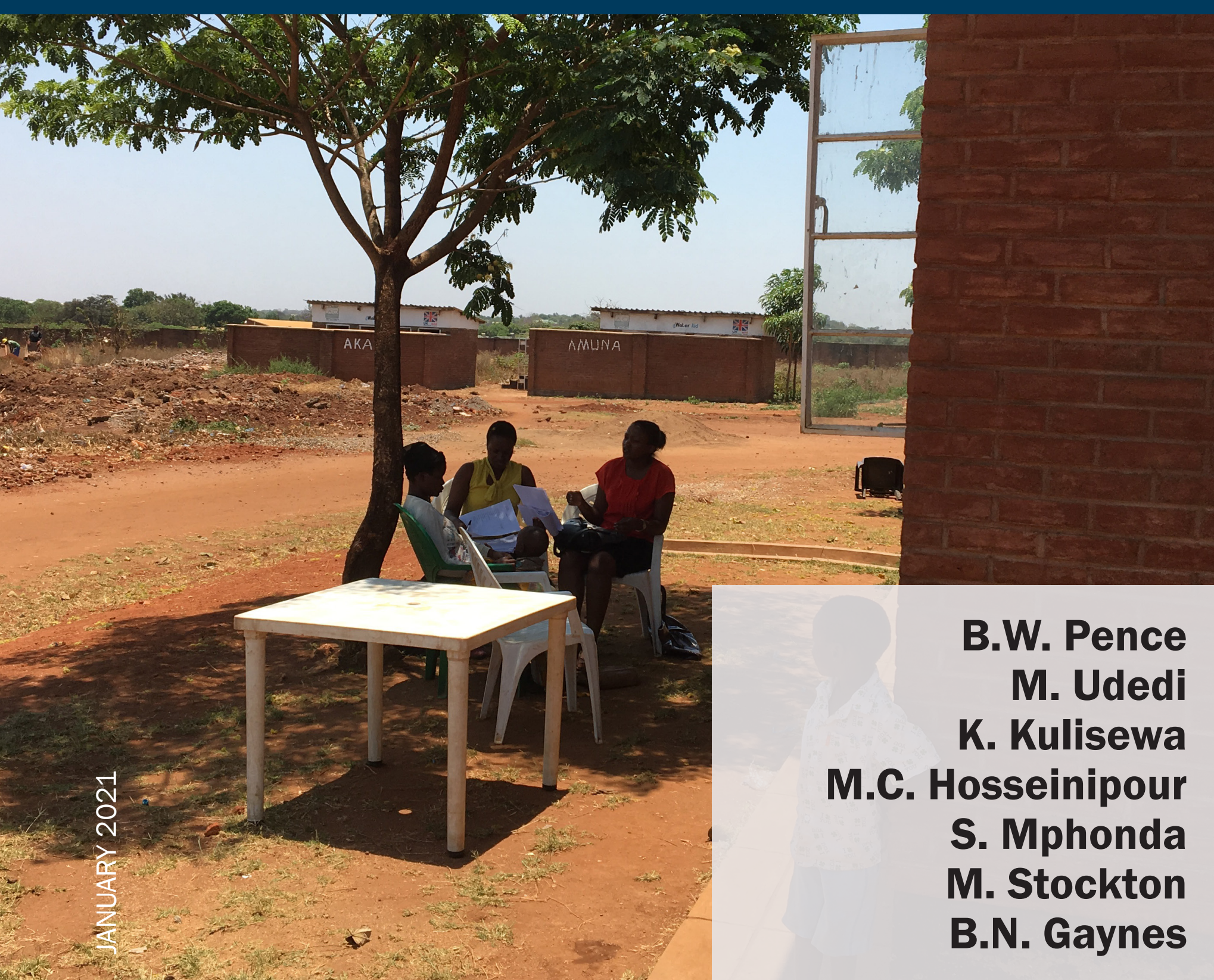

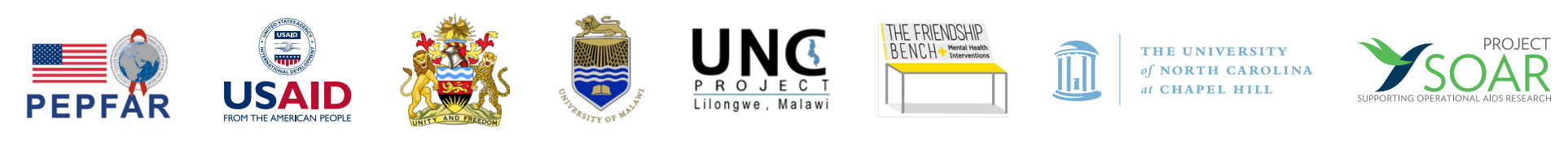


Project SOAR

Population Council

4301 Connecticut Ave, NW, Suite 280

Washington, D.C. 20008 USA

Tel: +1202 2379400

Fax: +1 2022378410

projsoar.org
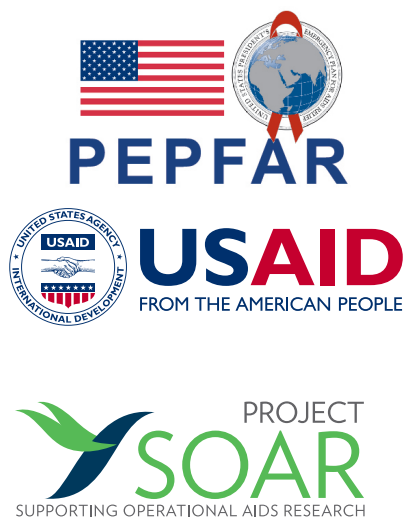

Project SOAR (Cooperative Agreement AID-OAA-A-14-00060) is made possible by the generous support of the American people through the United States President's Emergency Plan for AIDS Relief and the United States Agency for International Development (USAID). The contents of this report are the sole responsibility of Project SOAR and the Population Council and do not necessarily reflect the views of PEPFAR, USAID, or the United States Government.

Through operations research, Project SOAR will determine how best to address challenges and gaps that remain in the delivery of HIV and AIDS care and support, treatment, and prevention services. Project SOAR will produce a large, multifaceted body of high-quality evidence to guide the planning and implementation of HIV and AIDS programs and policies. Led by the Population Council, Project SOAR is implemented in collaboration with Avenir Health, Elizabeth Glaser Pediatric AIDS Foundation, Johns Hopkins University, Palladium, and The University of North Carolina.

The Population Council confronts critical health and development issues-from stopping the spread of HIV to improving reproductive health and ensuring that young people lead full and productive lives. Through biomedical, social science and public health research in about 50 countries, the Council works with our partners to deliver solutions that lead to more effective policies, programs, and technologies to improve lives worldwide. Established in 1952 and headquartered in New York, the Council is a nongovernmental, nonprofit organization with an international board of trustees.

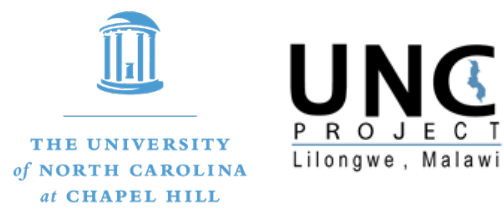

at CHAPEL HILL
The University of North Carolina Project-Malawi (UNC Project) is a collaboration between the University of North Carolina at Chapel Hill and the Malawi Ministry of Health with the mission to identify innovative, culturally acceptable, and affordable methods to improve the health of the people of Malawi, through research, capacity building, and clinical care.

Cover photo credit: (CBradley Gaynes, UNC School of Medicine

Published in January 2021. (C2021 The Population Council Inc.

Suggested citation: Pence, B.W., M. Udedi, K. Kulisewa, M.C. Hosseinipour, S. Mphonda, M. Stockton, and B.N. Gaynes. 2021. “Integrating depression management into HIV care in Lilongwe, Malawi: Feasibility and impact," Project SOAR Final Report. Washington, DC: USAID | Project SOAR. 


\section{Integrating Depression Management into HIV Care in Lilongwe, Malawi: Feasibility and impact}

B.W. Pence ${ }^{1}$, M. Udedi ${ }^{2}$, K. Kulisewa ${ }^{3}$, M.C. Hosseinipour ${ }^{1,4}$, S. Mphonda ${ }^{4}$, M. Stockton ${ }^{1}$, B.N. Gaynes ${ }^{1}$

${ }^{1}$ University of North Carolina, Chapel Hill, NC, USA

${ }^{2}$ Ministry of Health, Malawi

${ }^{3}$ College of Medicine, Malawi

${ }^{4}$ UNC Project-Malawi
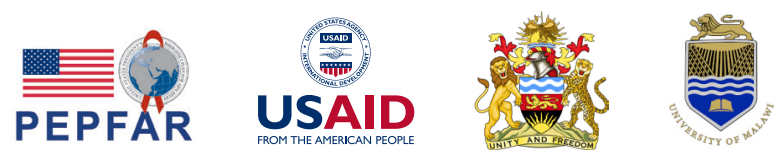


\section{ACKNOWLEDGMENTS}

We would like to express our gratitude to the participants who graciously allowed the use of their HIV and mental health clinical data to evaluate this program. We would also like to acknowledge the staff at the program sites for their willingness to participate in trainings and provide mental health screening and treatment. As well, we are especially appreciative of the collaboration with the Lilongwe District Health Office, Lighthouse Trust, and Baylor, which facilitated comprehensive training of the clinic staff. We would also like to thank our amazing program coordinator, Steve Mphonda, without whom the implementation of this project would not have been possible, as well as our fantastic team of research assistants, who worked tirelessly to consent participants and ensure the highest quality of data. Finally, thanks to the USAID OHA Adult care and treatment team members, led by Ilana Lapidos-Salaiz, for their vision, technical insight, and financial support. 


\section{TABLE OF CONTENTS}

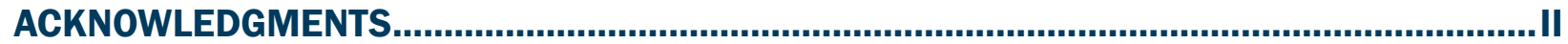

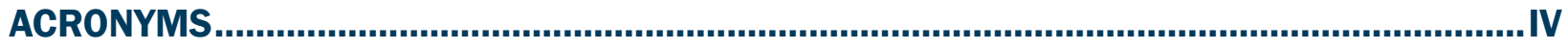

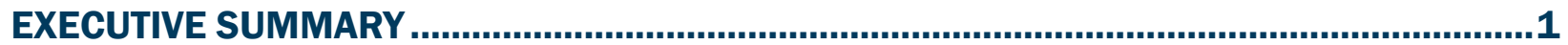

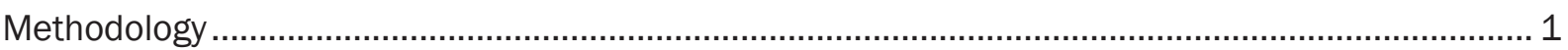

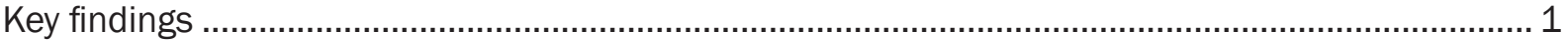

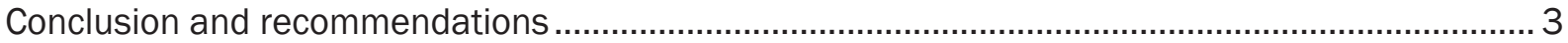

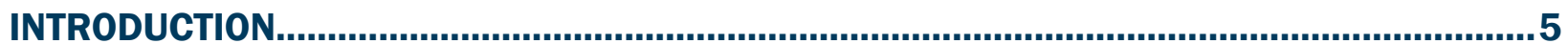

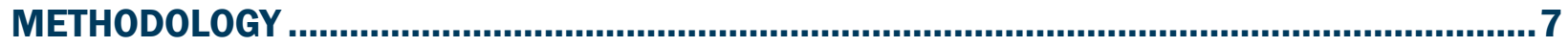

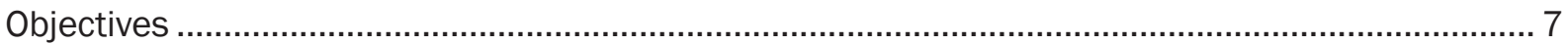

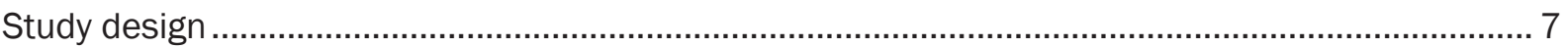

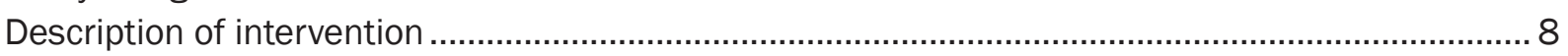

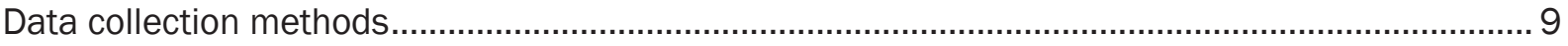

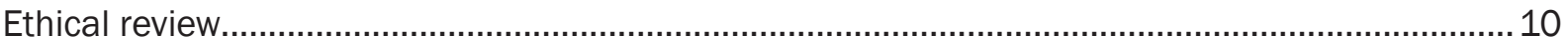

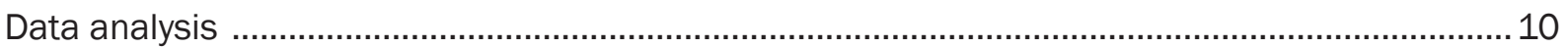

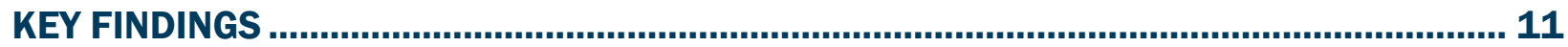

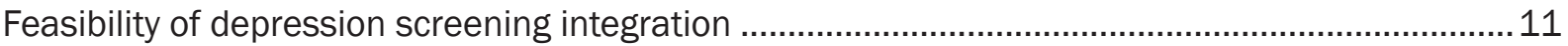

Feasibility of initiating depression treatment ……………………………………………....12

Consistency of HIV appointment attendance .......................................................................13

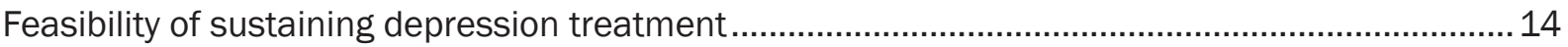

Program impact on HIV and depression outcomes …………..................................................15

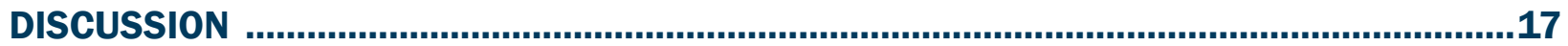

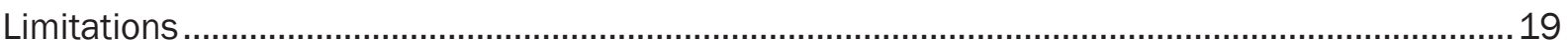

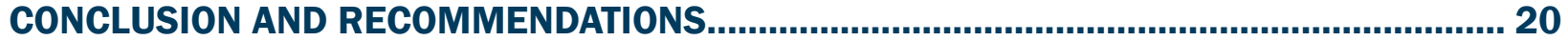

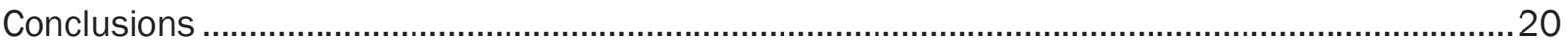

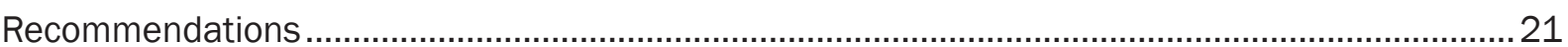

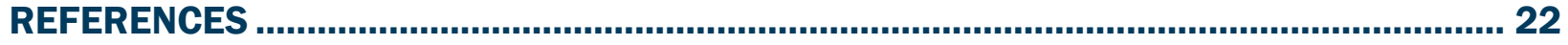

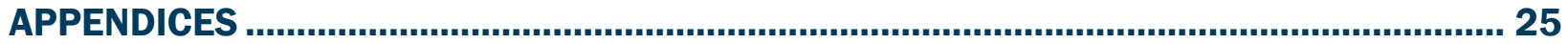

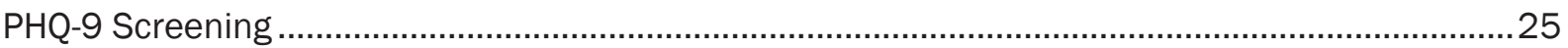

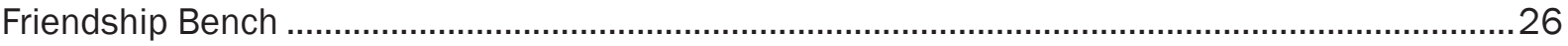

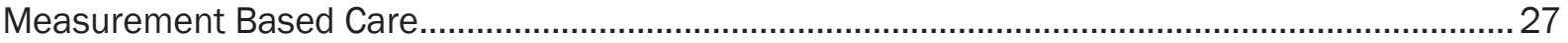




\section{ACRONYMS}

$A D$

ART

EMR

FB

HTC

HIV

HSA

IRB

MBC

$\mathrm{MOH}$

NCDs

NHSRC

PEPFAR

PHQ-9

PHQ-2

PST

SOAR

UNAIDS

UNC

USAID

WHO
Antidepressants

Antiretroviral treatment

Electronic medical record

Friendship bench

HIV testing and counseling

Human immunodeficiency virus

Health Surveillance Assistant

Institutional Review Board

Measurement Based Care

Ministry of Health

Non-communicable diseases

National Health Science Research Committee

United States President's Emergency Plan for AIDS Relief

Patient Health Questionnaire-9

Patient Health Questionnaire-2

Problem-solving therapy

Supporting Operational AIDS Research

Joint United Nations Programme on HIV/AIDS

University of North Carolina

United States Agency for International Development

World Health Organization 


\section{EXECUTIVE SUMMARY}

Depression is highly prevalent among people living with HIV in Malawi, as in other countries across the globe. Depression can undermine ART adherence, retention in care, and, ultimately, viral suppression. Identifying and treating depression may be key to improving engagement in care across the HIV care continuum.

In Malawi, as in other sub-Saharan countries, mental health care infrastructure and resources are limited. Accordingly, there is a clear need to shift the provision of mental health treatment to the primary care level. The Malawi Ministry of Health, in partnership with UNC Project-Malawi, designed a program that would integrate depression screening and management into HIV care at two public HIV clinics in Lilongwe, Malawi. The purpose of this study, conducted under Project SOAR, was to evaluate the implementation of this program and its impact on HIV and mental health outcomes.

\section{METHODOLOGY}

The primary objective of this study was to evaluate the impact of a practical, evidence-based mental health treatment program integrated with HIV care, feasible for scale-up within the Malawi health system, on mental health and HIV treatment outcomes. The program focused on training existing ART staff and providers to screen for depression and prescribe antidepressants and training existing lay health workers as depression counselors.

The study employed a pre-post multiple baseline design in two public health clinics in urban Lilongwe. All patients starting ART and identified as having mild, moderate, or severe depressive symptoms (PHQ-9 score $\geq 5$ ) during the screening phase were followed forward until six months after ART initiation for HIV appointment attendance, viral load, and depressive symptom outcomes. During the screening ("pre“) phase, depression screening was integrated into ART initiation and providers were re-oriented to existing depression treatment options. During the active ("post") phase, providers were additionally trained in algorithm-guided antidepressant prescription for moderate to severe depression, and lay health workers were trained in Friendship Bench problem-solving therapy for mild depression.

Data were collected from clinical records on HIV appointment attendance, viral suppression, and depressive symptoms during the first six months after ART initiation.

\section{KEY FINDINGS}

\section{Feasibility of integrating depression screening}

Depression screening proved highly feasible to integrate with ART initiation. Screening was divided such that the initial 2-item PHQ-2 screen was completed with the HIV post-test counselor, 
and only those with a positive PHQ-2 score went on to complete the full PHQ-9 with their HIV clinician. Overall, among 2,069 patients initiating ART during the study, 96 percent completed the full depression screening process; only 4 percent either did not complete the PHQ-2, or scored positive on the PHQ-2 and failed to complete the PHQ-9.

\section{Characteristics of patients}

Patient characteristics were comparable between the screening and active phases, supporting the argument that the study design appropriately controlled for confounding. In both phases slightly fewer than half of patients were male; the mean age was approximately 33.8 years; virtually all patients were asymptomatic (WHO Stage I); approximately 25 percent of patients had mild, moderate, or severe depressive severity; and approximately 5 percent of patients indicated passive or active suicidal thoughts.

\section{Feasibility of initiating depression treatment}

Depression treatment initiation also proved feasible to integrate into ART care. Of the 156 patients identified with mild depression during the active phase, 87 percent initiated Friendship Bench counseling. Of the 55 patients identified with moderate to severe depression, 96 percent initiated an antidepressant.

\section{Consistency of HIV appointment attendance}

Loss to HIV care was high. Fully one-quarter of patients did not return for their first ART refill appointment, and over half were out of care at six months. These results were comparable during the screening and active phases.

\section{Feasibility of sustaining depression treatment}

Sustaining depression treatment proved challenging, in part because many patients missed follow-up ART appointments or were quickly lost to care. Of the 140 patients who started the Friendship Bench, 57 percent attended at least two sessions and 33 percent attended at least four sessions out of the recommended six sessions. Although the Friendship Bench was originally designed as a weekly program, most patients cited time or financial barriers to making extra trips to the clinic and aligned follow-up counseling sessions with their monthly ART appointments. Of the 55 patients who were initially prescribed an antidepressant, 31 percent received at least three months of antidepressant prescriptions, while the remainder received only one or two months of medication before discontinuing.

\section{Program impact on HIV and depression outcomes}

Our primary outcome was HIV treatment success at six months, stringently defined as never more than two weeks late to a scheduled appointment in the first six months of care and a viral load $<1,000$ copies/mL at approximately six months post-ART initiation. There was no evidence of improved HIV treatment success in the active phase (18\%) relative to the screening phase (25\%). Similarly, no difference between the phases was evident in a range of secondary outcomes including being in care at six months, proportion of ART appointments attended within one week, 
consistent ART supply through six months, viral suppression at six months, and PHQ-9 depressive symptom severity score at six months.

\section{CONCLUSION AND RECOMMENDATIONS}

The SOAR-Malawi Mental Health Project demonstrated that it is feasible to integrate universal depression screening and evidence-based antidepressant management and problem-solving therapy counseling into routine care using existing staff in low-resource ART clinics in Malawi.

Different challenges were raised by integration of antidepressants and counseling. After a 1-day training, clinicians were comfortable initiating antidepressants and did so systematically with very little increased time cost. However, because of challenging medical record systems, returning patients on antidepressants were inconsistently identified and often did not have their depressive symptom level re-assessed or receive a refill of their antidepressant. Occasional stockouts also affected medication supply. Counseling, on the other hand, was not affected by stockouts or medical record challenges. However, counseling was significantly more time-intensive, and integration into the workload of existing staff proved infeasible. Further, follow-up for counseling was poor, and few patients ended up receiving the recommended six sessions.

A large proportion of patients missed HIV appointments or stopped coming altogether in both the screening and active phases. Among those who did remain in care, viral suppression and depression remission at six months were both very high. We saw no evidence of greater improvement in HIV care or mental health outcomes with the depression treatment program relative to the screening phase. This may have been because most depression at ART initiation was time-limited adjustment disorder, because even the basic one-time counseling provided during the screening phase was impactful, or because ART initiation and subsequent physical health improvement led to mental health improvement in both phases.

Several key recommendations arise from the SOAR-Malawi Mental Health Project.

First, efforts to integrate depression screening and treatment within routine ART care in resourcelimited settings are definitely feasible, but will greatly benefit from the following:

- A dedicated on-site champion with strong investment in program success either through financial support, strong institutional commitment, or other strategies.

- Integration with electronic medical record systems where feasible (many clinics in Malawi use the Baobab electronic system for ART records), which would ensure that screening is completed and returning patients on antidepressant treatment are identified and re-assessed.

- Dedicated counseling personnel (other research has demonstrated that community members, who may be willing to commit for a small stipend, can be trained and supervised to effectively deliver problem-solving therapy).

- Identification of appropriate and sustainable incentives (monetary or non-monetary) that will ensure that clinicians participate in clinical supervision sessions to maintain and enhance these new skills. 
- Identification of appropriate and sustainable means of support to encourage patients to complete the recommended weekly counseling sessions.

Second, this program did not find evidence that HIV care or mental health outcomes improved during the treatment program relative to the screening phase. While this program focused on patients newly initiating ART as a population at high risk for loss to care, depression treatment may be more important for returning patients who may present with more persistent or severe depressive symptoms and face challenges in maintaining long-term ART adherence and HIV care engagement. Therefore, programs that seek to integrate mental health screening and treatment into HIV primary care should not restrict themselves to new patients but should evaluate the mental health needs of all patients. 


\section{INTRODUCTION}

Depression is highly prevalent among people living with HIV in Malawi as in other countries across the globe. While research in Africa is limited, studies have found that depression affects 18 to 30 percent of people living with HIV (Nakimuli-Mpungu et al. 2011). In Malawi, the prevalence of depression among people living with HIV varies between 1 and 19 percent (Dow et al. 2014; Harrington et al. 2018; Kim et al. 2014; Malava et al. 2018). The high prevalence of depression among this vulnerable group indicates a need for mental health screening and treatment.

Depression can undermine ART adherence, retention in care, and, ultimately, viral suppression. Depression is a barrier to ART retention and is associated with reduced ART adherence and viral suppression (Franke et al. 2013; Gonzalez et al. 2011; Kidia et al. 2015; Nakimuli-Mpungu et al. 2011; Pence et al. 2007; Smillie et al. 2014) as well as greater perceived stigma and faster HIV clinical progression (Gonzalez et al. 2011; Ickovics et al. 2001; Leserman et al. 2007; Leserman 2008; Pence et al. 2007). Fortunately, some studies have shown that depression treatment may improve ART adherence and other HIV outcomes (Gaynes et al. 2015; Sin and DiMatteo 2014; Tsai et al. 2010; Walkup et al. 2008; Yun et al. 2005). Identifying and treating depression may be key to improving engagement in care across the HIV care continuum.

In Malawi, as in other sub-Saharan African countries, there are significant barriers to mental health care seeking and limited mental health care infrastructure and resources. Stigma, cultural beliefs around mental illness, and lack of knowledge of mental health all negatively impact access to mental health care services (Crabb et al. 2012; Udedi 2016). The country currently treats mental healthcare as a specialized service, often only provided by mental health specialists in specialized tertiary facilities. Furthermore, there are few such specialists and facilities; there are only three psychiatrists and three functioning public psychiatric hospitals in the country (Udedi et al. 2018). As it is unlikely that the number of specialized service providers and infrastructure could grow rapidly enough to meet the demands of the population, there is a clear need to shift the provision of mental health treatment to the primary care level.

Depression screening and management programs and tools for non-mental health specialists in Africa exist. Validated screening tools for depression, such as the Patient Health Questionnaire-9, are now available for the sub-Saharan region (Ali, Ryan, and De Silva 2016; Chorwe-Sungani and Chipps 2017). Depression treatment programs using antidepressant and psychosocial therapies have also been developed (Adams et al. 2012a; Adams et al. 2012b; Chibanda et al. 2011; Chibanda et al. 2016; Gaynes et al. 2015; Pence et al. 2014; Wagner, Slaughter, and GhoshDastidar 2017). Notably, in Cameroon, a measurement-based care program successfully treated depression among people living with HIV (Gaynes et al. 2015; Pence et al. 2014). In Zimbabwe, a problem-solving therapy intervention delivered by lay health workers proved efficacious in improving common mental disorders among patients in primary care in a large clusterrandomized trial (Chibanda et al. 2017; Chibanda et al. 2011; Chibanda et al. 2016). While such programs have proven to be efficacious, they are infrequently adapted, implemented, and evaluated in real-world programmatic contexts in the sub-Saharan region. 
The Malawi Ministry of Health (MOH) has committed to achieving the UNAIDS 90-90-90 goals, calling for 90 percent of those HIV-infected to be aware of their status, 90 percent of those aware of their status to be on sustained antiretroviral therapy (ART), and 90 percent of those on ART to be virally suppressed (UNAIDS 2014). Simultaneously, the noncommunicable diseases (NCDs) and Mental Health Unit of the Malawi $\mathrm{MOH}$ has prioritized the integration of mental health services into other general health services and the development of mental health capacity of general providers (Government of Malawi Ministry of Health 2013; Government of Malawi Ministry of Health 2017; Lupafya et al. 2016). The MOH, in partnership with UNC-Project Malawi, designed a program that would integrate depression screening and management into HIV care at two public HIV clinics in Lilongwe, Malawi. The purpose of this study, conducted under Project SOAR, was to evaluate the implementation of this program and its impact on HIV and mental health outcomes. 


\section{METHODOLOGY}

\section{OBJECTIVES}

The primary objective of this study was to evaluate the impact of a practical, evidence-based mental health treatment program integrated with HIV care, feasible for scale-up within the Malawi health system, on mental health and HIV treatment outcomes. Specifically, among all patients with mild, moderate, or severe depression, we aimed to evaluate the impact of the program on the following primary HIV outcomes:

- Proportion of patients attending sufficient HIV appointments to maintain ART supply through the first six months on ART (i.e., all monthly appointments through six months).

- Number of monthly HIV appointments attended in the first six months on ART.

- Proportion of patients with a HIV RNA viral load of $<1,000$ copies/mL approximately six months after starting ART.

We further focused on the following secondary mental health outcomes:

- Proportion of patients with remission of depressive symptoms, defined as a PHQ-9 score $<5$, at six months.

- Proportion of patients with a decrease of 50 percent or more in depressive symptoms from baseline to six months.

\section{STUDY DESIGN}

This study employed a pre-post multiple baseline design to evaluate the impact of integrating the depression treatment program within existing HIV clinical services on HIV and mental health outcomes (Figure 1). Working in two public health clinics in urban Lilongwe, we launched a Screening phase in both clinics in April and May 2017. The screening phase lasted 7 months at Clinic A and 11 months at Clinic B. All patients starting ART and identified as having mild, moderate, or severe depressive symptoms (PHQ-9 score $\geq 5$ ) during the screening phase were followed forward until six months after ART initiation for HIV appointment attendance, viral load, and depressive symptom outcomes, even if this follow-up extended into the second (active) phase.

At the conclusion of the screening phase, each clinic transitioned into the active phase. The active phase lasted 12 months at Clinic A and six months at Clinic B. All patients starting ART and identified as having mild, moderate, or severe depressive symptoms during the active phase were followed forward until six months after ART initiation for the same outcomes listed above.

The screening and active phases are described in more detail in the next section. 
Figure 1 Study design

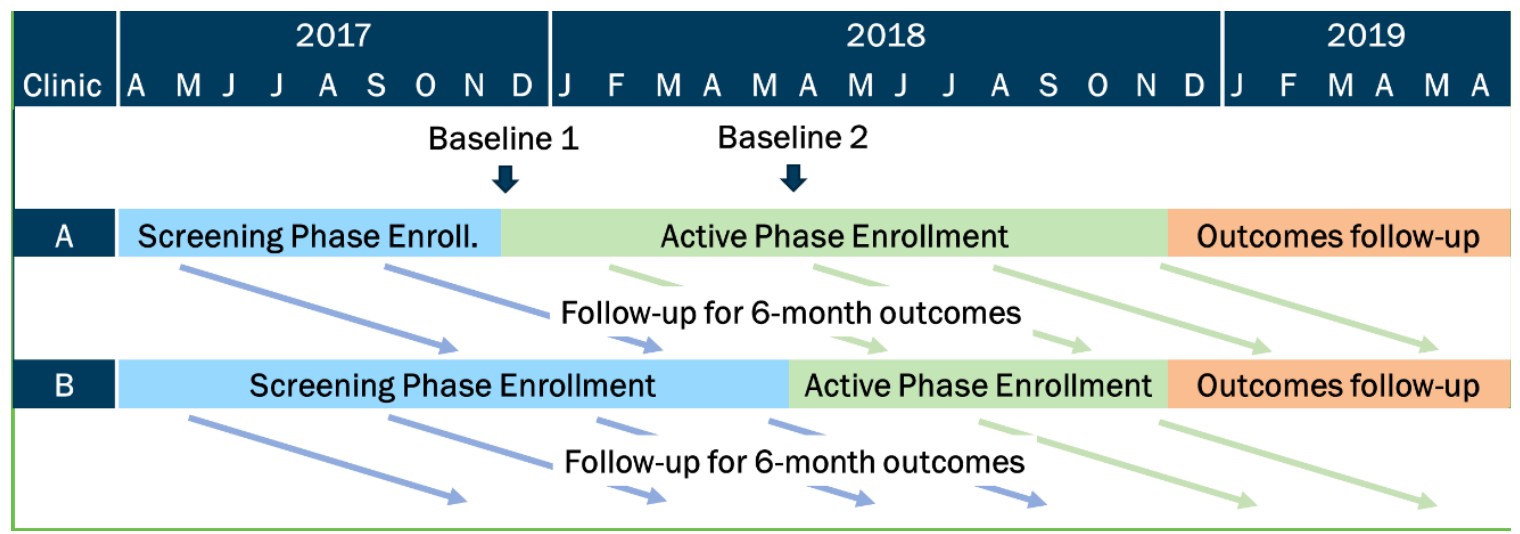

\section{DESCRIPTION OF INTERVENTION}

We integrated a depression screening and treatment program in two phases at two public HIV clinics in Lilongwe, Malawi.

The first phase, known as the "screening" phase, of the program launched in April 2017. During this phase, we trained existing HIV post-test counselors and HIV providers to screen patients for depression using the Patient Health Questionnaire-2 (PHQ-2) and, for those screening positive, complete further assessment with the PHQ-9 to identify depressive symptom severity. ART providers also received a refresher training on the existing care options for depression, typically brief, single-session counseling by the ART provider, referral to off-site specialized psychiatric services, or (rarely) prescription of amitriptyline. Amitriptyline was commonly available at both clinics during the screening phase, as it is used to treat peripheral neuropathy, but providers had limited familiarity with its use as an antidepressant and were most comfortable prescribing it at doses for peripheral neuropathy that would be subtherapeutic for depression. Fluoxetine was not available during the screening phase.

We also trained providers in assessment of and response to suicidal thoughts as indicated by any response other than "Never" on question 9 of the PHQ-9, which asks about any thoughts of being better off dead or considering hurting oneself in the past two weeks. For patients endorsing any such thoughts, providers were trained to complete a Suicide Risk Assessment form which guided them through evaluating whether such thoughts were passive (thoughts of being better off dead) or active (thoughts of actually hurting oneself), and the degree of severity of these thoughts or behaviors. Providers were trained in the appropriate response depending on the level of severity of the thoughts, ranging from brief safety assessment to immediate transport to the outpatient psychiatric department at a nearby hospital.

In the second phase, known as the "active" phase, ART providers were trained to provide algorithm-based care for depression (ABCD). ABCD directs providers to refer patients with mild depression for a problem-solving therapy intervention, while patients with moderate to severe depression are initiated on antidepressants using an algorithm known as Measurement Based Care $(\mathrm{MBC})$. The problem-solving therapy intervention received by patients with mild depression 
was the evidence-based psychosocial counseling strategy originally developed in Zimbabwe (The Friendship Bench) (Chibanda et al. 2011). The Friendship Bench tailored for the Malawi setting was intended to be six 30- to 45-minute sessions over six weeks and was delivered by clinic-based lay health workers, known as Health Surveillance Assistants (HSAs). There was no expectation that patients would necessarily see the same counselor from one session to the next, although patients and counselors could try to arrange for continuity if possible; staff availability was the primary driver of which counselor was seen at the patient's next return visit.

MBC directs providers to prescribe antidepressants (either fluoxetine or amitriptyline) and titrate the dose accordingly based on antidepressant side effects and depression symptom severity (PHQ-9 score) to patients with moderate to severe depression. ART providers re-administer the PHQ-9 to patients at their monthly ART visits to monitor their depressive symptoms and manage their treatment accordingly.

\section{DATA COLLECTION METHODS}

During both the screening and active phases, research assistants approached patients newly initiating ART and invited them to participate in the program evaluation. Consenting patients allowed the abstraction of their clinical data. To evaluate the impact of the program on HIV and mental health outcomes, we abstracted mental health and HIV data from consenting patients' clinical records from ART initiation up to a total of 13 months in care. Data included HIV appointment attendance, ART medication dispensed, HIV viral load results, depression treatment information (counseling sessions and antidepressants prescribed), and follow-up depressive symptom assessments.

Patients with depressive symptoms received care according to the current phase (screening or active) regardless of whether or not they provided consent for their data to be abstracted.

\section{Box 1 Screening phase vs active phase explained}

\section{Screening phase Active Phase}

Depression screening Integrated into HTC (PHQ-2 administered by counselors) and ART initiation (PHQ-9 completed by ART clinicians or nurses)

Depression treatment

No or minimal depression

Mild depression

Moderate to severe depression
Standard care

None

Potential to include additional counseling during ART, amitriptyline prescription (typically at subtherapeutic dose), or referral to mental health specialists
Algorithm-based care for depression

None

Friendship Bench counseling provided by trained HSAs

Measurement Based Care prescription of antidepressants (amitriptyline or fluoxetine) by ART clinicians or nurses 


\section{ETHICAL REVIEW}

The protocol was approved by the National Health Sciences Research Committee of Malawi (NHSRC) and the Biomedical Institutional Review Board (IRB) of the University of North Carolina at Chapel Hill. All research activities adhered to Malawian and US ethical standards for research in human subjects. To ensure protection of patients' identities and confidentiality, the study only used routinely collected, de-identified clinical data to evaluate this treatment program.

\section{DATA ANALYSIS}

We begin by comparing the characteristics of those enrolled in the screening vs. active phases to evaluate comparability of the two populations. We continue with descriptive information about depression screening, treatment initiation, and treatment continuation, as well as on HIV appointment attendance over the first six months on ART. We then compare the primary and secondary outcomes between the screening and active phases. 


\section{KEY FINDINGS}

\section{FEASIBILITY OF DEPRESSION SCREENING INTEGRATION}

Between April 2017 and November 2018, 2,414 patients newly initiated ART at the two study sites. Approximately 86 percent $(n=2,067$ ) of patients who newly initiated ART during this period consented to allow the abstraction of their clinical data to evaluate the program. Nearly all of consenting individuals $(n=2,063)$ were screened with the PHQ-2, and 96 percent of those screened with the PHQ-2 successfully completed depression screening. A quarter of the new ART initiators reported mild (19\%), moderate $(6 \%)$, or severe $(<1 \%)$ depressive symptoms (Figure 2).

Figure 2 Evaluation enrollment

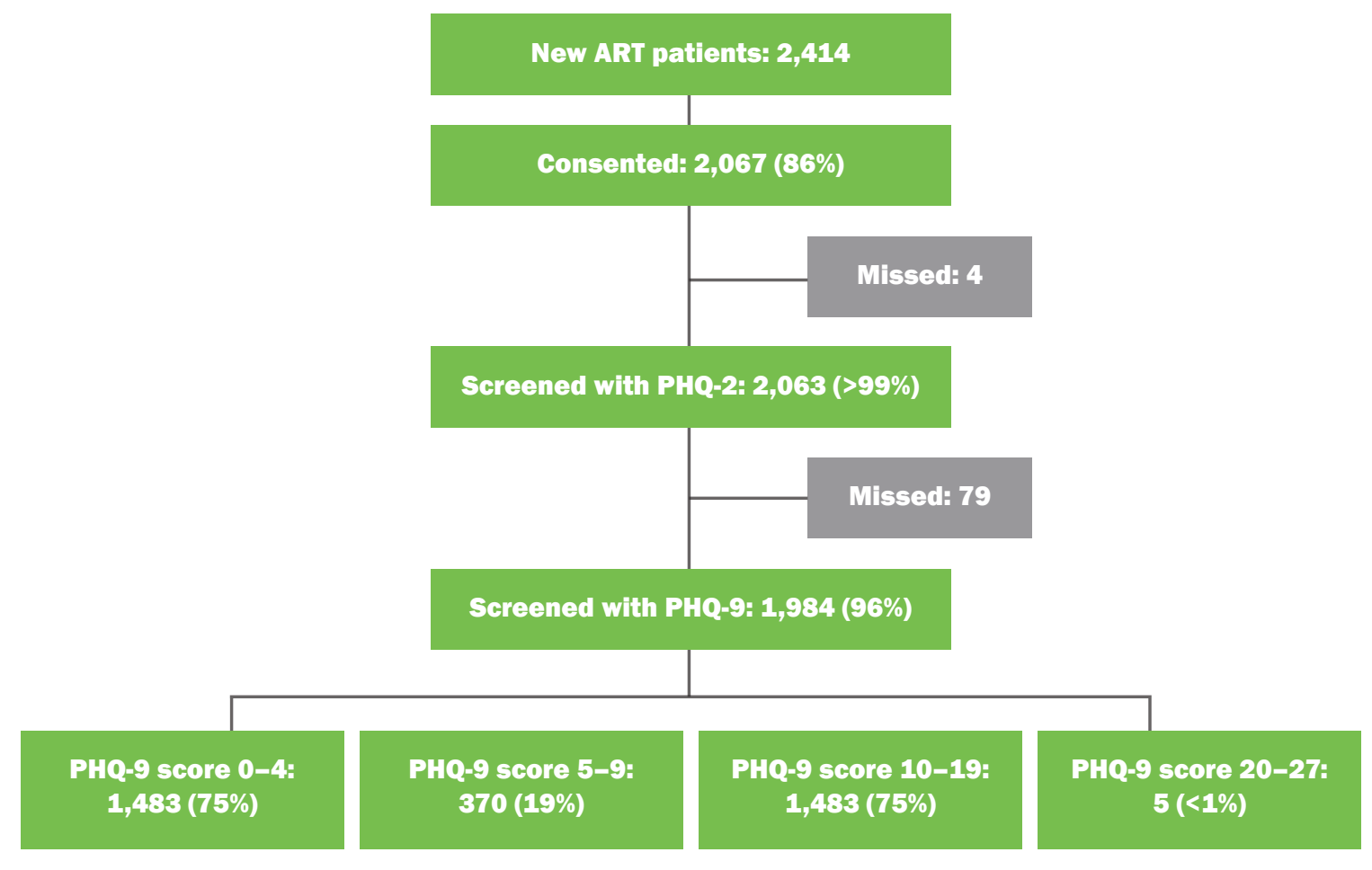

\section{CHARACTERISTICS OF CONSENTING PARTICIPANTS}

We enrolled 2,067 individuals in our program evaluation; 1,131 initiated during the screening phase and 936 initiated during the active phase (Table 2). Just under half of participants were male (47\%). The mean age of participants (33.8) did not vary appreciably between the screening and active phases. According to the World Health Organization's (WHO) HIV clinical stages for HIV surveillance (WHO 2005), nearly everyone $(\mathrm{N}=2,064)$ was classified as asymptomatic (Stage 1). Overall, 43 percent of participants scored above 0 on the PHQ-2, 19 percent reported mild depression (PHQ-9 score 5-9), and 7 percent reported moderate to severe depression (PHQ-9 
score $\geq 10$ ). The prevalence of suicidality was approximately 5 percent, with most being passive suicidal ideation. There were no notable differences by sex.

Table 2 Characteristics of consenting patients

\begin{tabular}{|c|c|c|c|}
\hline & $\begin{array}{c}\text { Overall } \\
\mathrm{n}(\%) \text { or mean (sd) }\end{array}$ & $\begin{array}{l}\text { Screening phase } \\
\text { n (\%) or mean (sd) }\end{array}$ & $\begin{array}{c}\text { Active phase } \\
\mathrm{n}(\%) \text { or mean (sd) }\end{array}$ \\
\hline Overall & 2,067 & 1,131 & 936 \\
\hline \multicolumn{4}{|l|}{ Clinic } \\
\hline Clinic A & $1,143(55 \%)$ & $460(41 \%)$ & $683(73 \%)$ \\
\hline Clinic B & $924(45 \%)$ & $671(59 \%)$ & $253(27 \%)$ \\
\hline \multicolumn{4}{|l|}{ Sex } \\
\hline Male & $980(47 \%)$ & $530(47 \%)$ & $450(48 \%)$ \\
\hline Female & $1,087(53 \%)$ & $601(53 \%)$ & $486(52 \%)$ \\
\hline Age & $33.8(9.3)$ & $33.5(9.6)$ & $34.2(8.9)$ \\
\hline \multicolumn{4}{|l|}{ WHO stage } \\
\hline I & $2,062(100 \%)$ & $1,129(100 \%)$ & $933(100 \%)$ \\
\hline II-IV & $5(0 \%)$ & $2(0 \%)$ & $3(0 \%)$ \\
\hline \multicolumn{4}{|l|}{ Depressive symptom severity } \\
\hline Screen-negative (PHQ-2 score $=0$ ) & $1,134(57 \%)$ & $602(55 \%)$ & $532(60 \%)$ \\
\hline Minimal symptoms (PHQ-9 score 1-4) & $349(18 \%)$ & $199(18 \%)$ & $150(17 \%)$ \\
\hline Mild symptoms (PHQ-9 score 5-9) & $370(19 \%)$ & $214(20 \%)$ & $156(17 \%)$ \\
\hline Moderate symptoms (PHQ-9 score 10-19) & $126(6 \%)$ & $71(6 \%)$ & $55(6 \%)$ \\
\hline Severe symptoms (PHQ-9 score $20-27$ ) & $5(0 \%)$ & $5(0 \%)$ & $0(0 \%)$ \\
\hline Not assessed & 83 & 40 & 43 \\
\hline \multicolumn{4}{|l|}{ Suicidal thoughts } \\
\hline No thoughts & $1,876(95 \%)$ & $1,026(94 \%)$ & $850(95 \%)$ \\
\hline Passive thoughts & $56(3 \%)$ & $35(3 \%)$ & $21(2 \%)$ \\
\hline Active thoughts & $46(2 \%)$ & $27(2 \%)$ & $19(2 \%)$ \\
\hline Not assessed & $6(0 \%)$ & $3(0 \%)$ & $3(0 \%)$ \\
\hline
\end{tabular}

\section{FEASIBILITY OF INITIATING DEPRESSION TREATMENT}

During the screening phase, the majority of patients both with mild and moderate to severe depression received brief counseling from their HIV clinician. During the active phase, 86 percent of participants with mild depressive symptoms started Friendship Bench counseling and 96 percent of participant with moderate to severe depressive symptoms started an antidepressant (Table 3). Treatment initiation indicators were comparable between the two clinics in the active phase. 
Table 3 Baseline depression treatment plan

\begin{tabular}{|lcc|}
\hline & $\begin{array}{c}\text { Screening Phase } \\
n(\%)\end{array}$ & $\begin{array}{c}\text { Active Phase } \\
\text { Mild depressive symptoms (PHQ-9 score 5-9)* }\end{array}$ \\
Counseling by HIV clinician & $214(100 \%)$ & $156(100 \%)$ \\
Counseling by Friendship Bench (FB) counselor & $191(89 \%)$ & $15(10 \%)$ \\
Antidepressant (AD) & $0(0 \%)$ & $134(86 \%)$ \\
AD \& clinician counseling & $1(0 \%)$ & $0(0 \%)$ \\
AD \& FB counseling & $1(0 \%)$ & $0(0 \%)$ \\
None* & $0(0 \%)$ & $2(1 \%)$ \\
Moderate to severe depressive symptoms (PHQ-9 score $\geq 10)$ & $21(10 \%)$ & $55(100 \%)$ \\
Counseling by HIV clinician & $76(100 \%)$ & $2(4 \%)$ \\
Counseling by FB counselor & $60(79 \%)$ & $0(0 \%)$ \\
AD & $0(0 \%)$ & $41(75 \%)$ \\
AD \& clinician counseling & $7(9 \%)$ & $8(15 \%)$ \\
AD \& FB counseling & $7(9 \%)$ & $4(7 \%)$ \\
None & $0(0 \%)$ & $0(0 \%)$ \\
\hline
\end{tabular}

*Those with missing baseline treatment plan $(n=4)$ treated as none; $A D=$ antidepressants, FB=Friendship Bench

\section{CONSISTENCY OF HIV APPOINTMENT ATTENDANCE}

After ART initiation, about three quarters of participants in both phases returned for their 1-month ART appointment whereas about one-quarter did not (28\% and $25 \%$ during the screening and active phase, respectively) (Figures $\mathbf{3} \boldsymbol{\&} \mathbf{4}$ ). Attendance continued to decline thereafter. By the 6-month appointment window, only 36 percent and 35 percent attended an appointment during the screening and active phase, respectively; another 10 percent (screening phase) and 6 percent (active phase) had been given a 60- or 90-day supply of ART at an earlier appointment and were not expected to attend at six months. A small number of patients were known to have died or transferred care, but a much larger proportion missed an appointment or were lost to care (defined as having gone at least 30 days without ART, i.e., the prior scheduled appointment was missed and the patient had gone at least 30 more days beyond the expected date of running out of ART without an attended appointment). These follow-up rates are fairly comparable to the clinic's overall retention rate, with about 44 percent of all patients during this period either attending an appointment or having an extended supply of ART (prior 60- or 90-day dispensed supply) at six months. There were no notable differences by sex. 
Figure 3 Screening phase: HIV appointment attendance during first 6 months on ART

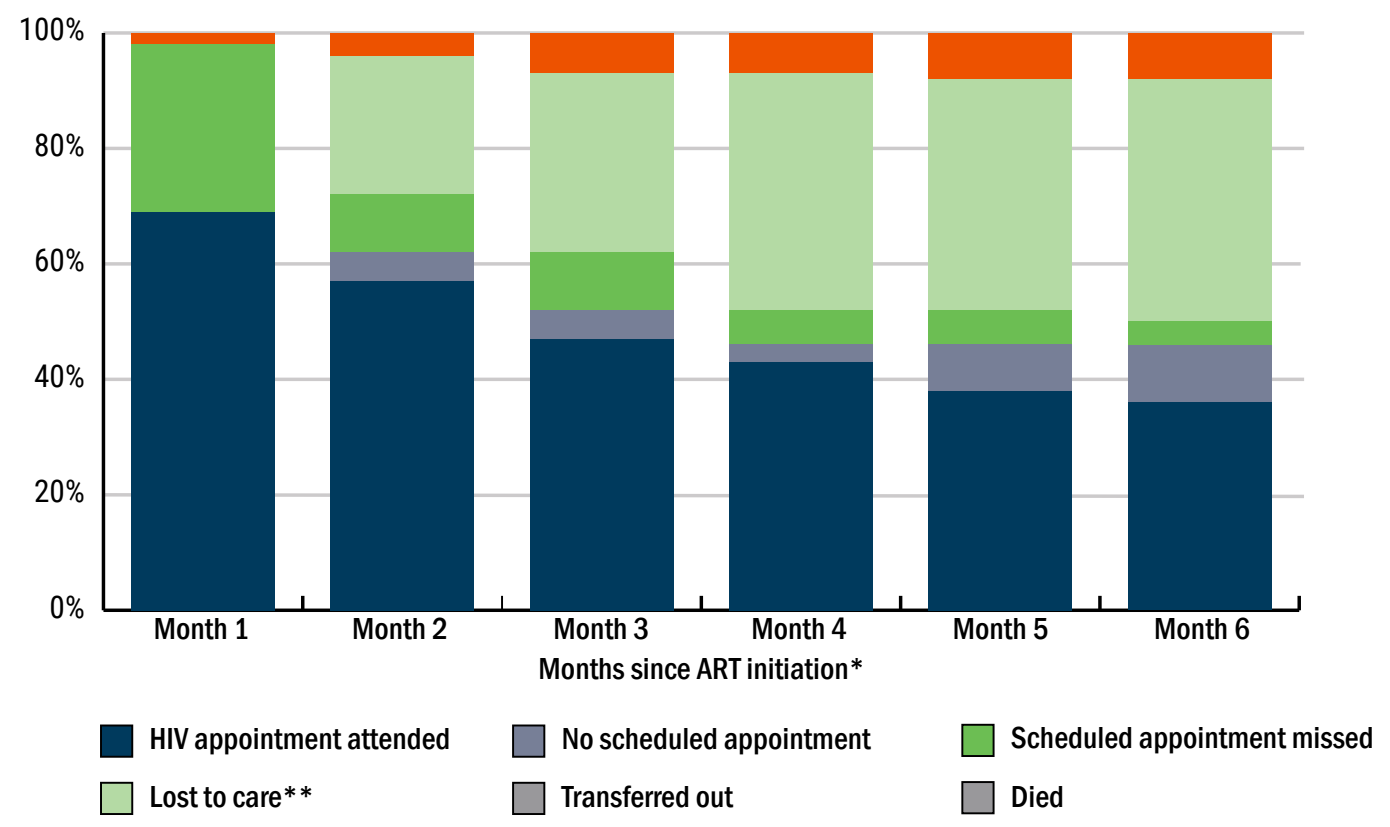

*Month 1=Days 1-45; Month 2=Days 46-76; Month 3=Days 77-106; Month 4=107-137; Month 5=138-167; Month 6=Days 168-197

**Patient has gone at least 30 days without ART, i.e., the prior scheduled appointment was missed and the patient had gone at least 30 more days beyond the expected date of running out of ART without an attended appointment

Figure 4 Active phase: HIV appointment attendance during first 6 months on ART

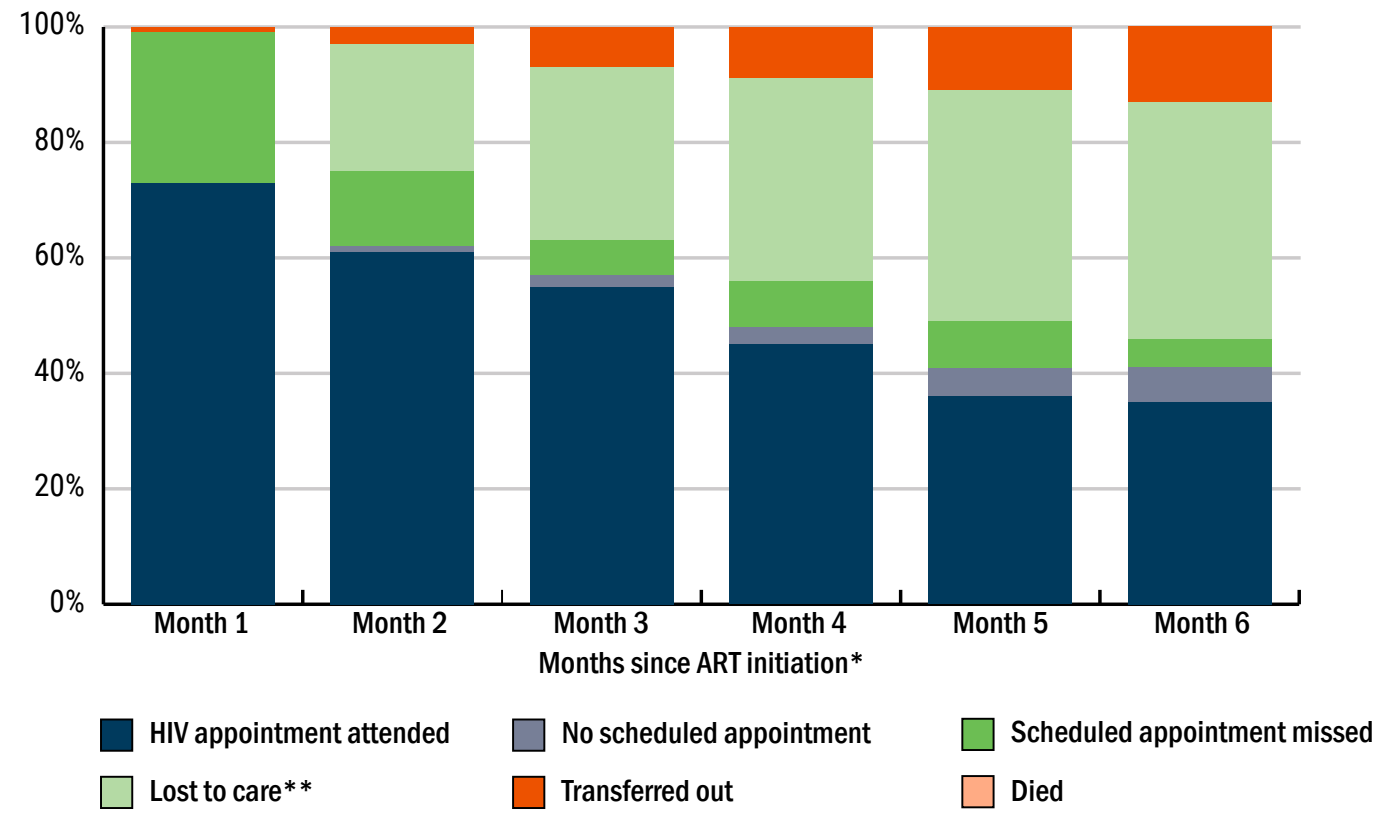

*Month 1=Days 1-45; Month 2=Days 46-76; Month 3=Days 77-106; Month 4=107-137; Month 5=138-167; Month 6=Days 168-197

**Patient has gone at least 30 days without ART, i.e., the prior scheduled appointment was missed and the patient had gone at least 30 more days beyond the expected date of running out of ART without an attended appointment 


\section{FEASIBILITY OF SUSTAINING DEPRESSION TREATMENT}

An adequate course of depression treatment consists of six Friendship Bench counseling sessions or at least three months of continuous antidepressant prescription with dosage adjustments if indicated. Few patients received an adequate course of treatment, in part due to the low overall HIV care retention rate and in part due to patients who attended clinic not receiving follow-up depression care; the majority of inadequate depression treatment was due to patients not returning to clinic, but a large proportion was also due to returning patients not being identified for follow-up care (Appendix figures 5 and 6). During the active phase, only around onethird of individuals who were directed to receive Friendship Bench counseling completed four or more sessions in their first six months of care (Table 4). In addition, only 18 percent $(n=10)$ of participants who were prescribed antidepressants at ART initiation received antidepressants at four or more sessions over their first six months of care. Of these five individuals, only two received four consecutive months of antidepressant prescriptions.

Table 4 Provision of depression treatment over first 6 months on ART

\begin{tabular}{|lc|cc|}
\hline & $\begin{array}{c}\text { Active phase } \\
\text { overall } \\
\text { Of those directed to FB counseling* }\end{array}$ & \multicolumn{2}{c|}{ Active phase } \\
Number of FB sessions attended & $140(100 \%)$ & $107(100 \%)$ & $33(100 \%)$ \\
1 & & & $29(88 \%)$ \\
2 & $60(43 \%)$ & $31(29 \%)$ & $2(6 \%)$ \\
3 & $21(15 \%)$ & $19(18 \%)$ & $1(3 \%)$ \\
$\geq 4$ & $13(9 \%)$ & $12(11 \%)$ & $1(3 \%)$ \\
Of those prescribed AD** & $46(33 \%)$ & $45(42 \%)$ & $11(100 \%)$ \\
Number of months of AD provided & $55(100 \%)$ & $44(100 \%)$ & $9(82 \%)$ \\
1 & $23(42 \%)$ & $14(32 \%)$ & $2(18 \%)$ \\
2 & $15(27 \%)$ & $13(30 \%)$ & $0(0 \%)$ \\
3 & $7(13 \%)$ & $7(16 \%)$ & $0(0 \%)$ \\
\hline 4 & $10(18 \%)$ & $10(23 \%)$ & 0 \\
\hline
\end{tabular}

$\mathrm{FB}=$ Friendship Bench; $\mathrm{AD}=$ Antidepressants

\section{PROGRAM IMPACT ON HIV AND DEPRESSION OUTCOMES}

The primary outcome of this evaluation was HIV clinical success. HIV clinical success was defined as meeting both of the following criteria: never more than two weeks late to a scheduled appointment in the first six months of care and a viral load $<1,000$ copies $/ \mathrm{mL}$ at the viral load assessment conducted at approximately six months post-ART initiation. Overall, only one-quarter of patients achieved HIV clinical success; 28 percent of patients from the screening phase and 22 percent of patients in the active phase (Table 5). There were no notable differences by sex. Approximately one-third of patients from both the screening and active phases were retained through six months (never more than two weeks late to a scheduled appointment in the first six months). Nearly every patient with a measured viral load demonstrated viral suppression at six months (94\% and $91 \%$ in screening and active phase, respectively). Similarly, nearly every patient with a 6-month PHQ-9 score achieved depression remission (94\% and 97\% in the screening and active phases, respectively). The HIV and depression outcomes did not vary appreciably between phases. 
Table 5 Program impact on HIV and depression outcomes among patients with mild, moderate, or severe depression at baseline

\begin{tabular}{|c|c|c|c|}
\hline & $\begin{array}{c}\text { Overall } \\
(n=502) \\
n(\%)\end{array}$ & $\begin{array}{l}\text { Screening } \\
\text { Phase } \\
(n=291) \\
n(\%)\end{array}$ & $\begin{array}{c}\text { Active Phase } \\
\qquad \begin{array}{c}(n=211) \\
n(\%)\end{array}\end{array}$ \\
\hline \multicolumn{4}{|l|}{ PRIMARY OUTCOME } \\
\hline \multicolumn{4}{|l|}{$\begin{array}{l}\text { HIV clinical success: Never }>14 \text { days late to an appointment } \\
\text { through } 6 \text { months and virally suppressed at } 6 \text { months }\end{array}$} \\
\hline Yes & 102 (25\%) & $68(28 \%)$ & $34(22 \%)$ \\
\hline No & 301 (75\%) & $178(72 \%)$ & $123(78 \%)$ \\
\hline Retained, but missing viral load & 49 & 20 & 29 \\
\hline Transferred out & 49 & 24 & 25 \\
\hline \multicolumn{4}{|l|}{ SECONDARY OUTCOMES } \\
\hline \multicolumn{4}{|l|}{$\begin{array}{l}\text { Retained through } 6 \text { months: Never }>14 \text { days late to an } \\
\text { appointment }\end{array}$} \\
\hline Yes & 157 (35\%) & 91 (34\%) & $66(35 \%)$ \\
\hline No & 295 (67\%) & $175(66 \%)$ & $120(65 \%)$ \\
\hline Transferred out & 49 & 24 & 25 \\
\hline \multicolumn{4}{|l|}{$\begin{array}{l}\text { Currently on ART: Attended an appointment prior to } 6 \text { months with } \\
\text { a next appointment date after } 6 \text { months }\end{array}$} \\
\hline Yes & 225 (50\%) & $138(52 \%)$ & 87 (46\%) \\
\hline No & 227 (50\%) & $128(48 \%)$ & 99 (54\%) \\
\hline Transferred & 49 & 24 & 25 \\
\hline $\begin{array}{l}\text { Proportion of scheduled HIV appointments attended within } 1 \text { week } \\
\text { [Mean (SD)] }\end{array}$ & $0.57(0.39)$ & $0.57(0.39)$ & $0.59(0.38)$ \\
\hline \multicolumn{4}{|l|}{$\begin{array}{l}\text { Consistent ART supply through } 6 \text { months: Never }>5 \text { days without } \\
\text { ART }\end{array}$} \\
\hline Yes & 185 (41\%) & $112(42 \%)$ & $73(39 \%)$ \\
\hline No & 267 (59\%) & $154(58 \%)$ & $113(61 \%)$ \\
\hline Transferred out & 49 & 24 & 25 \\
\hline ART pill possession ratio* [Mean (SD)] & $0.68(0.36)$ & $0.69(0.35)$ & $0.67(0.37)$ \\
\hline \multicolumn{4}{|l|}{ Virally suppressed at 6 months** } \\
\hline Yes & $168(93 \%)$ & $108(94 \%)$ & $60(91 \%)$ \\
\hline No & $13(7 \%)$ & $7(6 \%)$ & $6(9 \%)$ \\
\hline Retained, but no VL drawn & 74 & 39 & 35 \\
\hline No attended appointment between months 5.5 and 8 & 197 & 112 & 85 \\
\hline Transferred out & 49 & 24 & 25 \\
\hline \multicolumn{4}{|l|}{ Depression remission (PHQ-9 score $<5$ ) at 6 months } \\
\hline Yes & 124 (95\%) & 87 (94\%) & $37(97 \%)$ \\
\hline No & $7(5 \%)$ & $6(6 \%)$ & $1(3 \%)$ \\
\hline Attended appointment but no PHQ-9 completed & 110 & 51 & 59 \\
\hline No attended appointment between months 5.5 and 8 & 211 & 122 & 89 \\
\hline Transferred out & 49 & 24 & 25 \\
\hline PHQ-9 score at 6 months** [Mean (SD)] & $1.0(2.4)$ & $1.2(2.7)$ & $0.6(1.4)$ \\
\hline
\end{tabular}

VL=Viral Load; SD=Standard Deviation

*Proportion of 6 months (183 days) with ART. Numerator is the cumulative number of pills dispensed through 6 months. Pills dispensed at last visit before 6-month prorated to be equivalent to the number of days between that visit and day 183 in care.

** Take from the first viral load/PHQ-9 after at least 5.5 months in care 


\section{DISCUSSION}

The objective of this study was to integrate a practical, feasible depression treatment program into routine, real-world HIV care in Malawi and evaluate the impact of that integration on HIV and mental health outcomes for patients newly initiating ART. The program was highly successful in effectively integrating depression screening, assessment, and treatment initiation using existing staff, but faced greater challenges in ensuring continuity of depression care at follow-up visits. Generally, loss to HIV care was very high both before and after the program implementation, but those patients retained in HIV care almost universally demonstrated viral suppression and depression remission. There was no evidence of greater improvement in HIV or mental health outcomes under the integrated program compared to the pre-implementation screening phase.

We were able to successfully integrate depression screening and treatment initiation into starting HIV care. Over the course of this program, nearly all new ART initiators were screened for depression with the PHQ-2, and 92 percent of patients with positive PHQ-2 screens completed the PHQ-9. About one-quarter of study participants had mild to severe depression at ART initiation. While a high percentage of participants started the appropriate depression treatment during the active phase, few patients continued to receive counseling or antidepressants over their first six months of care.

We attribute the success in integration of depression screening and treatment initiation to several factors. First, we found that effectively utilizing existing ART initiation processes and infrastructure was key (Udedi et al. 2018). For example, after careful study of the clinic flow, the additional work and time burden of screening patients and initiating treatment was split across the HIV post-test counselors and HIV providers. Additionally, we invested heavily in creating multiple opportunities for iterative and collaborative learning (Udedi et al. 2018). We ensured that every HIV provider received training in how to administer and interpret the PHQ-9, provide depression treatment, and manage depressive symptoms over time.

However, sustaining depression management was challenging for the health care facilities. This was in part due to structural challenges. At these clinics, providers typically use an electronic medical record (EMR) system to manage ART care, with a parallel paper system populated with barcodes from the EMR. As resources were lacking to build a depression module into the ART EMR, we modified the paper recordkeeping system to track both ART and depression indicators. Nevertheless, providers struggled to re-identify depressed patients returning for care so as to provide appropriate follow-up. While the program team and the clinic staff worked together to engineer a solution for this challenge by marking patients' health passports, ultimately it was difficult to overcome.

Furthermore, antidepressant stock-outs were common. Ostensibly, Malawi's Essential Health Package guarantees the availability of fluoxetine and amitriptyline free of charge for patients at public clinics in Malawi (Government of Malawi Ministry of Health 2013). However, in practice ensuring their availability at the clinic proved complicated, requiring substantial coordination 
between the providers, the clinic pharmacies, the clinic leadership, the district health officer, the district health office pharmacy, and the national level medication reserves, often facilitated by project staff. Other countries in the region such as Mozambique also have an essential drug list that includes amitriptyline and fluoxetine; however, a recent study found that these drugs were not frequently available at the district or clinic level (Wagenaar et al. 2015).

The clinics also faced some difficulties ensuring provision of Friendship Bench counseling with existing staff. While the study did hire one dedicated Friendship Bench counselor at each clinic, these study counselors were meant to provide back-up for the larger group of $\mathrm{MOH}$-employed community health workers trained as counselors. However, the study-employed counselors ultimately provided the majority of the counseling at both sites, as the community health workers had a very high workload and often traveled off-site to run various Ministry of Health initiatives. Furthermore, while the original Friendship Bench protocol called for six weeks of weekly Friendship Bench counseling sessions, nearly all patients were unable or unwilling to make extra trips to the clinic for counseling sessions without compensation due to time and transportation costs. As a result, nearly all of the Friendship Bench counseling sessions were provided monthly, on the same day at the ART appointment, which may have impacted the effectiveness of the counseling protocol. Future efforts to implement counseling protocols such as the Friendship Bench should consider carefully (1) the capacity of the cadre designated to provide the counseling and (2) how to support patients in regular attendance at sessions, for example with transportation assistance or possibly community-based delivery of counseling.

This population proved a very challenging group to keep engaged in treatment. We observed very high rates of loss to HIV care at both clinics, with only about one-quarter of participants remaining consistently in care for the first six months and having a suppressed viral load. Even when considering a somewhat more lenient definition of having ART at six months, fully half of patients did not meet this definition. However, of those attending appointments and with viral loads drawn around six months, nearly all were virally suppressed in both phases. These and several other secondary measures of HIV care engagement showed no notable difference between the screening and active phases. There are several possible explanations for this result. First, those patients identified with depressive symptoms at ART initiation may have had a timelimited reactive depression or adjustment disorder rather than major depressive disorder, which may have resolved independently of treatment in both phases. Indeed, depression remission was extremely high among those who stayed in care and had a completed PHQ-9 around six months-both among those with mild and those with moderate to severe depression at baseline. Second, for patients with no prior exposure to any sort of mental health care, even the very basic clinician-delivered counseling provided during the screening phase may have led to depression improvements, reducing the difference between the two arms. Ethically, it was not possible to have a pure "usual care" phase where patients were screened and identified with depression but no information was provided to clinicians and no clinical follow-up was permitted. Third, depressive symptoms may have improved for all patients with the initiation of antiretroviral therapy and the subsequent improvement in physical health. Indeed, several studies have found such improvements among ART initiators in Africa (Okeke and Wagner 2013, Wagner et al. 2012). This improvement may have masked the added benefit of the depression treatment program in this population. Finally, although uptake of depression screening and depression treatment initiation were high, achieving sustained depression treatment for multiple months proved 
challenging in this real-world context, which may also have limited the difference between the screening and active phases.

\section{LIMITATIONS}

Our results should be carefully considered in light of several limitations. First, since the primary outcome of the study was retention in HIV care, the study team intentionally did not schedule research follow-up interviews, especially for the 6-month outcome, that could have had the unintended effect of bringing participants back to clinic during the first six months and influencing the primary outcome. Therefore. the extent of participants without 6-month viral load and depression measures was greater than it would have been had the research team scheduled follow-ups with participants. If those who did not remain in care were more likely to have persistent depressive symptoms, the rate of depression remission reported here would be an overestimate. Further, PHQ-9s at 6-month follow-up were administered by clinicians as part of routine care. It is possible that part of the reduction in PHQ-9 scores observed between baseline and six months reflected less careful administration by clinicians at the later time point.

The primary objective of the study was to estimate the impact of the depression treatment program on HIV outcomes among the full patient population at the clinic. Since the primary outcome could be assessed purely relying on medical chart data, the team decided not to include a baseline patient interview that would have limited enrollment to those willing to spend the additional time for the interview. As a result, very limited information is available on potential confounders. However, the multiple baseline design should have protected against confounding by producing balanced characteristics of patients in the screening and active phases; indeed, all measured characteristics were very similar between the two phases.

Causal inference from this study relies on the validity of the multiple baseline design and specifically the comparability of the patient population at each clinic during the screening and active phases (or lack of confounding). As noted above, lack of confounding is supported by the comparable distributions of measured characteristics between the screening and active phases.

Although the primary outcome used for this study (attending sufficient HIV appointments to maintain ART supply through six months and having a suppressed viral load at six months) is more stringent than the standard PEPFAR definition of retention in care, we saw similar results with several different definitions of HIV care engagement, including the standard PEPFAR measure (Table 5).

Finally, the primary outcome of retention in HIV care may have been influenced by "silent transfers," or patients who switched care to another ART clinic without formally transferring their records. Patients who requested record transfers were recorded as transfers, but any patients who transferred silently would have been potentially misclassified as being out of care. However, there is no reason to believe that the rate of silent transfers would have varied between the screening and active phases, and therefore this potential measurement error should not have introduced bias into the primary analyses. 


\section{CONCLUSION AND RECOMMENDATIONS}

\section{CONCLUSIONS}

The SOAR-Malawi Mental Health Project demonstrated that it is feasible to integrate universal depression screening and evidence-based antidepressant management and problem-solving therapy counseling into routine care using existing staff in low-resource ART clinics in Malawi. Although there was some initial resistance from clinicians to added work with no added pay, with persistence and involvement of clinic leadership the program was successful in achieving over 90 percent coverage of depression screening and over 90 percent initiation of depression treatment among those identified with elevated depressive symptoms over an 18-month period.

Although clinicians and staff received no extra pay or incentives, this success was not resourcefree. Beyond the one-time costs for training, success hinged on significant legwork and "championing" by the study coordinator. Further, the training of existing Health Surveillance Assistants (clinic-based lay health workers) as problem-solving therapy counselors was not effective. Despite multiple efforts to organize rosters and ensure a shared workload, the existing HSAs were routinely pulled into other duties and not available for counseling. As a result, the study-funded counselor at each clinic did the vast majority of counseling sessions.

Different challenges were raised by integration of antidepressants and counseling. After a oneday training, clinicians were comfortable initiating antidepressants and did so systematically with very little increased time cost. However, because of challenging medical record systems, returning patients on antidepressants were inconsistently identified and often did not have their depressive symptom level re-assessed or receive a refill of their antidepressant. Further, although both amitriptyline and fluoxetine are on the government essential medications list, stockouts did occur, leading to medications being either discontinued or switched to the available antidepressant for some patients. In addition, although regular supervision is a critical aspect of supporting non-specialists in delivering depression care, very few clinicians attended the biweekly clinical supervisions held by the study team (for which no allowance was offered), even after multiple interventions with clinic and district leadership.

Counseling, on the other hand, was not affected by stockouts or medical record challenges since patients knew where to find the counselor. However, counseling was significantly more timeintensive, and integration into the workload of existing staff proved infeasible. Further, follow-up for counseling was poor. Patients, facing time and transportation costs, proved unable or unwilling to come to more frequent counseling sessions without travel reimbursement. As a result, counseling sessions occurred monthly at ART appointments rather than weekly as recommended, and few patients ended up receiving the recommended six sessions. 
Retention in HIV care through the first six months on ART was poor at our two clinics in both the screening and active phases. Among those who did remain in care, viral suppression and depression remission at six months were both very high. We saw no evidence of improved HIV care or mental health outcomes with the depression treatment program relative to the screening phase. This may have been because most depression at ART initiation was time-limited adjustment disorder, because even the basic one-time counseling provided during the screening phase was impactful, or because ART initiation and subsequent physical health improvement led to mental health improvement in both phases.

\section{RECOMMENDATIONS}

Several key recommendations arise from the SOAR-Malawi Mental Health Project.

First, efforts to integrate depression screening and treatment within routine ART care in resourcelimited settings are definitely feasible, but will greatly benefit from the following:

- A dedicated, funded on-site champion.

- Integration with electronic medical record systems where feasible (many clinics in Malawi use the Baobab Health electronic system for ART records), which would ensure that screening is completed and returning patients on antidepressant treatment are identified and re-assessed.

- Dedicated counseling personnel (other research has demonstrated that community members, who may be willing to commit for a small stipend, can be trained and supervised to effectively deliver problem-solving therapy).

- Identification of appropriate and sustainable incentives (monetary or non-monetary) that will ensure that clinicians participate in clinical supervision sessions to maintain and enhance these new skills.

- Identification of appropriate and sustainable means of support to encourage patients to complete the recommended weekly counseling sessions.

Second, this program did not find evidence that HIV care or mental health outcomes improved during the treatment program relative to the screening phase. While this program focused on patients newly initiating ART as a population at high risk for loss to care, depression treatment may be more important for returning patients who may present with more persistent or severe depressive symptoms and face challenges in maintaining long-term ART adherence and HIV care engagement.

Third, efforts to integrate depression care into HIV clinical services may need to consider the evolving ART delivery landscape, with increasing emphasis on reducing clinical appointments by providing multiple months' ART supply and expanding community ART delivery. Integration efforts may need to be creative about where and when to engage patients in depression screening and care, and potentially consider different follow-up schedules for patients on stable ART without complications vs. patients who require more frequent follow-up for management of comorbidities such as mental health. 


\section{REFERENCES}

Abas, M. et al. 2016. “'Opening up the mind': Problem-solving therapy delivered by female lay health workers to improve access to evidence-based care for depression and other common mental disorders through the Friendship Bench Project in Zimbabwe,“ International Journal of Mental Health Systems 10: 39. doi: 10.1186/ s13033-016-0071-9.

Adams, Julie L. et al. 2012a. "Feasibility of nurse-led antidepressant medication management of depression in an HIV clinic in Tanzania,“ International Journal of Psychiatry Medicine 43(2): 105-17. doi: 10.2190/PM.43.2.a

Ali, Gemma-Claire, Grace Ryan, and Mary J De Silva. 2016. "Validated screening tools for common mental disorders in low and middle income countries: A systematic review," PLoS One 11(6): e0156939. doi: 10.1371/ journal.pone.0156939

American Psychiatric Association. 2000. Diagnostic and Statistical Manual of Mental Disorders. 4th (Text Revision) Edition. Washington, DC: American Psychiatric Association.

Chibanda, Dixon et al. 2017. "Lay health workers' experience of delivering a problem solving therapy intervention for common mental disorders among people living with HIV: A qualitative study from Zimbabwe," Community Mental Health Journal 53(2): 143-153 doi: 10.1007/s10597-016-0018-2.

Chibanda, Dixon et al. 2016. "Effect of a primary care-based psychological intervention on symptoms of common mental disorders in Zimbabwe: A randomized clinical trial,“ JAMA 316(24): 2618-2626. doi: 10.1001/ jama.2016.19102

Chibanda, Dixon et al. 2011. "Problem-solving therapy for depression and common mental disorders in Zimbabwe: Piloting a task-shifting primary mental health care intervention in a population with a high prevalence of people living with HIV,“ BMC Public Health 11(1): 828. doi: 10.1186/1471-2458-11-828

Cholera, Rushina et al. 2014. "Validity of the Patient Health Questionnaire-9 to screen for depression in a high-HIV burden primary healthcare clinic in Johannesburg, South Africa,“ Journal of Affective Disorders 167: 160-66. doi: 10.1016/j.jad.2014.06.003

Chorwe-Sungani, Genesis and Jennifer Chipps. 2017. "A systematic review of screening instruments for depression for use in antenatal services in low resource settings, " BMC Psychiatry 17(1): 112. doi: 10.1186/s12888-0171273-7

Crabb, Jim et al. 2012. "Attitudes towards mental illness in Malawi: A cross-sectional survey," BMC Public Health 12(1): 541. doi: 10.1186/1471-2458-12-541

Dow, A., Q. Dube, B. W. Pence, and A. Van Rie. 2014. "Postpartum depression and HIV infection among women in Malawi,“ Journal of Acquired Immune Deficiency Syndrome 65(3): 359-65. doi: 10.1097/ QAI.0000000000000050

Franke, M. F. et al. 2013. "Improved retention associated with community-based accompaniment for antiretroviral therapy delivery in rural Rwanda," Clinical Infectious Diseases 56(9): 1319-26. doi: 10.1093/cid/cis1193

Gaynes, B. N. et al. 2015. "Changes in HIV outcomes following depression care in a resource-limited setting: Results from a pilot study in Bamenda, Cameroon," PLoS One 10(10):e0140001. doi: 10.1371/journal. pone.0140001.

Gelaye, Bizu et al. 2013. "Validity of the Patient Health Questionnaire-9 for depression screening and diagnosis in East Africa,“ Psychiatry Research 210(2): 653-61. doi: 10.1016/j.psychres.2013.07.015

Gonzalez, J. S. et al. 2011. "Depression and HIV/AIDS treatment nonadherence: A review and meta-analysis," Journal of Acquired Immune Deficiency Syndrome 58(2): 181-7. doi: 10.1097/QAl.0b013e31822d490a.

Government of Malawi Ministry of Health. 2013. "The National Action Plan for NCDs and Mental Health (20122016).“ Lilongwe, Malawi: Government of Malawi Ministry of Health.

Government of Malawi Ministry of Health. 2017. "Malawi Health Sector Strategic Plan II 2017-2022: Towards universal health coverage." Lilongwe, Malawi: Government of Malawi Ministry of Health. 
Harrington, Bryna J. et al. 2018. "Prevalence and incidence of probable perinatal depression among women enrolled in Option B+ antenatal HIV care in Malawi,“ Journal of Affective Disorders 239:115-122. doi: 10.1016/j. jad.2018.06.001

Ickovics, J. R. et al. 2001. "Mortality, CD4 cell count decline, and depressive symptoms among HIV-seropositive women: Longitudinal analysis from the HIV epidemiology research study,“ JAMA 285(11): 1466-74. doi: 10.1001/ jama.285.11.1466

Kidia, K. et al. 2015. “'I was thinking too much': Experiences of HIV-positive adults with common mental disorders and poor adherence to antiretroviral therapy in Zimbabwe," Tropical Medicine \& International Health 20(7): 90313. doi: 10.1111/tmi.12502.

Kim, Maria H. et al. 2014. "Prevalence of depression and validation of the Beck Depression Inventory-II and the Children's Depression Inventory-Short amongst HIV-positive adolescents in Malawi, "Journal of the International AIDS Society 17(1): 18965. doi: 10.7448/IAS.17.1.18965

Kroenke, K, RL Spitzer, and JB Williams. 2001. "The PHQ-9: Validity of a brief depression severity measure," Journal of General Internal Medicine 16(9): 606-13. doi: 10.1046/j.1525-1497.2001.016009606.x

Leserman, J. et al. 2007. "Relation of lifetime trauma and depressive symptoms to mortality in HIV, “ American Journal of Psychiatry 164(11): 1707-13. doi: 10.1176/appi.ajp.2007.06111775.

Leserman, J. 2008. "Role of depression, stress, and trauma in HIV disease progression," Psychosomatic Medicine 70(5): 539-45. doi: 10.1097/PSY.0b013e3181777a5f

Lupafya, Phindile Chitsulo et al. 2016. “Implementation of policies and strategies for control of noncommunicable diseases in Malawi: Challenges and opportunities," Health Education \& Behavior 43(1 Suppl): 64S-69S. doi: $10.1177 / 1090198115614313$.

Malava, Jullita K. et al. 2018. "Prevalence and correlates of probable depression diagnosis and suicidality among patients receiving HIV care in Lilongwe, Malawi,“ Malawi Medical Journal 30(4): 236-242. doi: 10.4314/mmj. v30i4.5.

Monahan, Patrick O. et al. 2009. "Validity/reliability of PHQ-9 and PHQ-2 depression scales among adults living with HIV/AIDS in Western Kenya,“ Journal of General Internal Medicine 24(2): 189-97. doi: 10.1007/s11606008-0846-z.

Nakimuli-Mpungu, E. et al. 2011. "Depression, alcohol use and adherence to antiretroviral therapy in sub-Saharan Africa: A systematic review,“ AIDS \& Behavior 16(8): 2101-18. doi: 10.1007/s10461-011-0087-8.

Okeke, E. N. and G. J. Wagner. 2013. "AIDS treatment and mental health: Evidence from Uganda," Social Science \& Medicine 92: 27-34. doi: 10.1016/j.socscimed.2013.05.018.

Pence, B. W. et al. 2007. "Psychiatric illness and virologic response in patients initiating highly active antiretroviral therapy," Journal of Acquired Immune Deficiency Syndromes 44(2): 159-66. doi: 10.1097/ QAI.0b013e31802c2f51.

Pence, B. W. et al. 2014. "Feasibility, safety, acceptability, and preliminary efficacy of measurement-based care depression treatment for HIV patients in Bamenda, Cameroon," AIDS \& Behavior 18(6): 1142-51. doi: 10.1007/ s10461-014-0727-x

Pierce, D. 2012. "Problem solving therapy-use and effectiveness in general practice," Australian Family Physician 41(9): 676-9.

Sin, N. L. and M. R. DiMatteo. 2014. "Depression treatment enhances adherence to antiretroviral therapy: A metaanalysis," Annals of Behavioral Medicine 47(3): 259-69. doi: 10.1007/s12160-013-9559-6.

Smillie, K. et al. 2014. "Mobile health for early retention in HIV care: A qualitative study in Kenya (Weltel Retain)," African Journal of AIDS Research 13(4): 331-8. doi: 10.2989/16085906.2014.961939.

Tsai, A. C. et al. 2010. "A marginal structural model to estimate the causal effect of antidepressant medication treatment on viral suppression among homeless and marginally housed persons with HIV," Archives Of General Psychiatry 67(12): 1282-90. doi: 10.1001/archgenpsychiatry.2010.160.

Udedi, M. et al. 2018. “Integrating depression management into HIV primary care in central Malawi: The implementation of a pilot capacity building program," BMC Health Services Research 18(1): 593. doi: 10.1186/ s12913-018-3388-z. 
Udedi, Michael. 2016. "Improving access to mental health services in Malawi," Ministry of Health Policy Brief.

UNAIDS. 2014. "90-90-90: An ambitious treatment target to help end the AIDS epidemic." Geneva: UNAIDS. Available at http://www.unaids.org/sites/default/files/media_asset/90-90-90_en_0.pdf. Accessed 12/7/2015. Congress.

Wagenaar, Bradley H. et al. 2015. "The availability of essential medicines for mental healthcare in Sofala, Mozambique," Global Health Action 8(1): 27942. doi: 10.3402/gha.v8.27942

Wagner, G. J. et al. 2012. "Impact of HIV antiretroviral therapy on depression and mental health among clients with HIV in Uganda," Psychosomatic Medicine 74(9): 883-90. doi: 10.1097/PSY.0b013e31826629db

Wagner, G. J. et al. 2016. "A structured protocol model of depression care versus clinical acumen: A cluster randomized trial of the effects on depression screening, diagnostic evaluation, and treatment uptake in Ugandan HIV clinics," PLoS One 11(5): e0153132. doi: 10.1371/journal.pone.0153132

Wagner, Glenn J., Mary Slaughter, and Bonnie Ghosh-Dastidar. 2017. "Depression at treatment initiation predicts HIV antiretroviral adherence in Uganda," Journal of the International Association of Providers of AIDS Care 16(1): 91-97. doi: 10.1177/2325957416677121

Walkup, J. et al. 2008. "Antidepressant treatment and adherence to combination antiretroviral therapy among patients with AIDS and diagnosed depression," Psychiatric Quarterly 79(1): 43-53.

World Health Organization. 2005. "Interim WHO clinical staging of HIV/AIDS and HIV/AIDS case definitions for surveillance: African Region.” Geneva: World Health Organization.

Yun, L. W. et al. 2005. "Antidepressant treatment improves adherence to antiretroviral therapy among depressed HIV-infected patients," Journal of Acquired Immune Deficiency Syndromes 38(4): 432-38. doi: 10.1097/01. qai.0000147524.19122.fd 


\section{APPENDICES}

\section{PHQ-9 SCREENING}

The Patient Health Questionnaire-9 (PHQ-9) is a widely used nine item instrument that assesses the presence of nine symptoms of depression within the previous two weeks as specified by the Diagnostic and Statistical Manual of Mental Disorders IV (American Psychiatric Association 2000). Each of the nine items is scored from 0 (not at all) to 3 (nearly every day). The first two questions-known as the Patient Health Questionnaire-2 (PHQ-2)-capture depressed mood and anhedonia, the two core symptoms of depression. A total score of 5-9, 10-14, 15-19, or 20 and above are considered indicative of mild, moderate, moderately severe, or severe depression, respectively (Kroenke, Spitzer and Williams 2001).

The HIV testing and counseling (HTC) providers screened patients with the PHQ-2 after a positive test for HIV. ART providers then screened patients who scored above 0 on the PHQ-2 with the remaining seven questions of the PHQ-9, assessing for the presence of the remaining seven symptoms of depression. ART providers then used the PHQ-9 to reassess patients for depression at their subsequent ART follow-up visits.

The PHQ-9 is one of a number of mental health screening tools that have been used in Malawi and other African countries. It was chosen because it focuses specifically on depression, has been widely used and validated in many different settings (Gelaye et al. 2013), and works well both as a screening tool for depression as well as a longitudinal measure to monitor response to treatment. This tool had been validated for use in HIV-positive populations in other countries in the region (Cholera et al. 2014, Monahan et al. 2009) and had been used in one other study in Malawi (Malava et al. 2018). It has since been validated among a population of people living with diabetes. The standard PHQ-9 was augmented with an additional screening protocol to probe the degree of severity of suicidality in patients who screened positive for suicidal ideation on the PHQ-9. Both the PHQ-9 and associated suicide risk assessment protocol were translated into Chichewa, the vernacular language in the central region of Malawi. This entailed an iterative process involving the health workers to ensure that the PHQ-9 adequately captures the depressive symptoms yet is culturally understandable. The translated instrument is currently being validated. 


\section{Patient Health Questionnaire-9}

\begin{tabular}{|c|c|c|c|c|c|}
\hline \multirow{2}{*}{$\begin{array}{l}\text { Ǹ } \\
\text { ơ } \\
\text { a }\end{array}$} & $\begin{array}{l}\text { 1. During the past two weeks, how many days have } \\
\text { you been bothered by feeling down, depressed, or } \\
\text { hopeless? }\end{array}$ & $\begin{array}{l}0 \text { days } \\
(0)\end{array}$ & $\begin{array}{c}\text { 1-7 days } \\
\text { (1) }\end{array}$ & $\begin{array}{c}8-12 \text { days } \\
\text { (2) }\end{array}$ & $\begin{array}{c}13 \text { or } 14 \text { days } \\
\text { (3) }\end{array}$ \\
\hline & $\begin{array}{l}\text { 2. During the past two weeks, how many days have } \\
\text { you been bothered by little interest or pleasure in } \\
\text { doing things? }\end{array}$ & $\begin{array}{l}0 \text { days } \\
(0)\end{array}$ & $\begin{array}{c}\text { 1-7 days } \\
\text { (1) }\end{array}$ & $\begin{array}{c}8-12 \text { days } \\
\text { (2) }\end{array}$ & $\begin{array}{c}13 \text { or } 14 \text { days } \\
\text { (3) }\end{array}$ \\
\hline \multirow{7}{*}{$\begin{array}{l}\text { o } \\
\text { ơ } \\
\text { ㅁ }\end{array}$} & $\begin{array}{l}\text { 3. During the past two weeks, how many days have } \\
\text { you been bothered by trouble falling or staying asleep, } \\
\text { or sleeping too much? }\end{array}$ & $\begin{array}{l}0 \text { days } \\
(0)\end{array}$ & $\begin{array}{c}\text { 1-7 days } \\
\text { (1) }\end{array}$ & $\begin{array}{c}8-12 \text { days } \\
(2)\end{array}$ & $\begin{array}{c}13 \text { or } 14 \text { days } \\
\text { (3) }\end{array}$ \\
\hline & $\begin{array}{l}\text { 4. During the past two weeks, how many days have } \\
\text { you been bothered by feeling tired, fatigued or having } \\
\text { little energy? }\end{array}$ & $\begin{array}{c}0 \text { days } \\
(0)\end{array}$ & $\begin{array}{c}\text { 1-7 days } \\
\text { (1) }\end{array}$ & $\begin{array}{c}8-12 \text { days } \\
(2)\end{array}$ & $\begin{array}{c}13 \text { or } 14 \text { days } \\
\text { (3) }\end{array}$ \\
\hline & $\begin{array}{l}\text { 5. During the past two weeks, how many days have } \\
\text { you been bothered by poor appetite or overeating? }\end{array}$ & $\begin{array}{l}0 \text { days } \\
(0)\end{array}$ & $\begin{array}{l}1-7 \text { days } \\
\text { (1) }\end{array}$ & $\begin{array}{l}8-12 \text { days } \\
(2)\end{array}$ & $\begin{array}{l}13 \text { or } 14 \text { days } \\
\text { (3) }\end{array}$ \\
\hline & $\begin{array}{l}\text { 6. During the past two weeks, how many days have } \\
\text { you been bothered by feeling bad about yourself-or } \\
\text { that you are a failure or have let yourself or your family } \\
\text { down? }\end{array}$ & $\begin{array}{l}0 \text { days } \\
(0)\end{array}$ & $\begin{array}{l}\text { 1-7 days } \\
\text { (1) }\end{array}$ & $\begin{array}{l}8-12 \text { days } \\
(2)\end{array}$ & $\begin{array}{l}13 \text { or } 14 \text { days } \\
\text { (3) }\end{array}$ \\
\hline & $\begin{array}{l}\text { 7. During the past two weeks, how many days have } \\
\text { you been bothered by trouble concentrating on things, } \\
\text { such as reading, talking with friends, finishing tasks, } \\
\text { or attending a meeting? }\end{array}$ & $\begin{array}{l}0 \text { days } \\
(0)\end{array}$ & $\begin{array}{l}1-7 \text { days } \\
\text { (1) }\end{array}$ & $\begin{array}{l}8-12 \text { days } \\
(2)\end{array}$ & $\begin{array}{l}13 \text { or } 14 \text { days } \\
\text { (3) }\end{array}$ \\
\hline & $\begin{array}{l}\text { 8. During the past two weeks, how many days } \\
\text { have you been bothered by moving or speaking so } \\
\text { slowly that other people could have noticed? Or the } \\
\text { opposite-being so fidgety or restless that you have } \\
\text { been moving around a lot more than usual? }\end{array}$ & $\begin{array}{l}0 \text { days } \\
(0)\end{array}$ & $\begin{array}{l}\text { 1-7 days } \\
\text { (1) }\end{array}$ & $\begin{array}{l}8-12 \text { days } \\
(2)\end{array}$ & $\begin{array}{l}13 \text { or } 14 \text { days } \\
\text { (3) }\end{array}$ \\
\hline & $\begin{array}{l}\text { 9. During the past two weeks, how many days have } \\
\text { you been bothered by thoughts that you would be } \\
\text { better off dead or of hurting yourself in some way? }\end{array}$ & $\begin{array}{l}0 \text { days } \\
(0)\end{array}$ & $\begin{array}{c}1-7 \text { days } \\
\text { (1) }\end{array}$ & $\begin{array}{c}8-12 \text { days } \\
(2)\end{array}$ & $\begin{array}{c}13 \text { or } 14 \text { days } \\
\text { (3) }\end{array}$ \\
\hline
\end{tabular}

\section{FRIENDSHIP BENCH}

The Friendship Bench therapy is an adapted form of problem-solving therapy that was developed over many years of formative research in Zimbabwe (Abas et al. 2016, Chibanda et al. 2011, Chibanda et al. 2016, Pierce 2012). Friendship Bench therapy consists of patient-centered counseling that teaches patients how to identify triggers and effectively manage stressful life events by learning or reactivating problem-solving skills. Specifically, counselors guide patients through recognizing problems, identifying their own solutions, implementing those solutions, and assessing the outcome (Chibanda et al. 2011, Pierce 2012). The original Friendship Bench was designed to be delivered by lay health care workers and called for patients to receive six 
weekly counseling sessions. However, in line with the patient-centered approach, patients were encouraged to set their own return dates.

During the active intervention phase of the program, ART providers were trained to refer participants with mild depressive symptoms (PHQ-9 score 5-9) to clinic-based lay health workers, called HSAs, or a project-employed counselor trained to provide Friendship Bench Therapy. The first session would often last about 45 minutes to an hour and subsequent sessions would be shorter (around 15 to 30 minutes). Patients referred to the Friendship Bench would ideally receive at least six counseling sessions over their first six months in care. Again, patients were encouraged to return weekly for Friendship Bench therapy, but ultimately patients set their own appointments in line with the protocol's patient-centered approach. The program built covered shelters with seating areas at both clinics to serve as the Friendship Bench in an effort ensure there would be a dedicated space for the Friendship Bench counselors to work.

\section{MEASUREMENT BASED CARE}

Measurement Based Care (MBC) is a resource-efficient, task-sharing model for prescribing antidepressant management in non-psychiatric settings. This model of care has demonstrated safety, feasibility, and acceptability when adapted for HIV care and delivered by general practice medical providers in Cameroon, Tanzania, and Uganda (Adams et al. 2012a, Pence et al. 2014, Wagner et al. 2016). The model of care uses PHQ-9 scores to monitor depressive symptoms in combination with an assessment of side effects and antidepressant tolerability to guide antidepressant prescription.

During the active intervention phase, ART providers prescribed antidepressants to patients with moderate to severe depression (PHQ-9 $\geq 10$ ). At the subsequent follow-up visits, ART providers would reassess patients' depressive symptoms with the PHQ-9 and assess the medication's tolerability. Providers would use changes in depressive symptoms and medication tolerability to guide management of patients' antidepressant prescription, with options to increase or decrease the dose or change the type of antidepressant prescribed.

Depression screening coverage, by clinic and period
\begin{tabular}{|lcccccc|}
\hline & $\begin{array}{c}\text { Initiating } \\
\text { ART } \\
\text { N }\end{array}$ & $\begin{array}{c}\text { Completing } \\
\text { PHQ-2 } \\
n(\%)\end{array}$ & $\begin{array}{c}\text { With PHQ-2 } \\
\text { score }>0 \\
n(\%)\end{array}$ & $\begin{array}{c}\text { Completing } \\
\text { PHQ-9 } \\
n(\%)\end{array}$ & $\begin{array}{c}\text { With PHQ-9 } \\
\text { score } \geq 5 \\
n(\%)\end{array}$ & $\begin{array}{c}\text { Overall } \\
\text { prevalence of } \\
\text { any depressive } \\
\text { symptoms } \\
\text { Patients: }\end{array}$ \\
Overall & 2,414 & $2,216(92 \%)$ & $952(43 \%)$ & $862(91 \%)$ & $502(58 \%)$ & $502(24 \%)$ \\
Clinic A & 1,370 & $1,259(92 \%)$ & $557(44 \%)$ & $487(87 \%)$ & $276(57 \%)$ & $276(23 \%)$ \\
Clinic B & 1,044 & $957(92 \%)$ & $395(41 \%)$ & $375(95 \%)$ & $226(60 \%)$ & $226(24 \%)$ \\
Screening phase & 1,308 & $1,182(90 \%)$ & $533(45 \%)$ & $488(92 \%)$ & $287(59 \%)$ & $287(25 \%)$ \\
Active phase & 11,06 & $1,034(93 \%)$ & $419(41 \%)$ & $374(89 \%)$ & $215(57 \%)$ & $215(22 \%)$ \\
\hline
\end{tabular}


Study population, by clinic and period

\begin{tabular}{|c|c|c|c|c|c|c|c|}
\hline & \multirow{2}{*}{$\begin{array}{c}\text { Overall } \\
n(\%) \text { or } \\
\text { mean (sd) }\end{array}$} & \multirow{2}{*}{$\begin{array}{l}\text { Screening } \\
\text { phase } \\
n(\%) \text { or } \\
\text { mean (sd) }\end{array}$} & \multirow{2}{*}{$\begin{array}{c}\text { Active phase } \\
n(\%) \text { or } \\
\text { mean }(\mathrm{sd})\end{array}$} & \multicolumn{2}{|c|}{ Screening phase } & \multicolumn{2}{|c|}{ Active phase } \\
\hline & & & & $\begin{array}{c}\text { Clinic A } \\
n(\%) \text { or } \\
\text { mean (sd) }\end{array}$ & $\begin{array}{c}\text { Clinic B } \\
n(\%) \text { or } \\
\text { mean (sd) }\end{array}$ & $\begin{array}{c}\text { Clinic A } \\
n(\%) \text { or } \\
\text { mean }(\mathrm{sd})\end{array}$ & $\begin{array}{c}\text { Clinic B } \\
n(\%) \text { or } \\
\text { mean (sd) }\end{array}$ \\
\hline Overall [N] & 2,067 & 1131 & 936 & 460 & 671 & 683 & 253 \\
\hline \multicolumn{8}{|l|}{ Clinic } \\
\hline Clinic A & $1,143(55 \%)$ & $460(41 \%)$ & $683(73 \%)$ & 460 (100\%) & - & $683(100 \%)$ & - \\
\hline Clinic B & $924(45 \%)$ & 671 (59\%) & $253(27 \%)$ & - & $671(100 \%)$ & - & $253(38 \%)$ \\
\hline \multicolumn{8}{|l|}{ Phase } \\
\hline Screening & - & - & - & 460 (100\%) & $671(100 \%)$ & - & - \\
\hline Active & - & - & - & - & - & $683(100 \%)$ & 253 (38\%) \\
\hline \multicolumn{8}{|l|}{ Sex } \\
\hline Male & 980 (47\%) & $530(47 \%)$ & 450 (48\%) & $228(50 \%)$ & 302 (45\%) & $340(50 \%)$ & $110(43 \%)$ \\
\hline Female & 1,087 (53\%) & $601(53 \%)$ & $486(52 \%)$ & 232 (50\%) & 369 (55\%) & $343(50 \%)$ & $143(57 \%)$ \\
\hline Age & $33.8(9.3)$ & $33.5(9.6)$ & $34.2(8.9)$ & $33.9(9.5)$ & $33.1(9.7)$ & $34.7(9.0)$ & $32.9(8.5)$ \\
\hline \multicolumn{8}{|l|}{ WHO disease stage } \\
\hline I & $2,062(100 \%)$ & $1,129(100 \%)$ & 933 (100\%) & 458 (100\%) & $671(100 \%)$ & $680(100 \%)$ & 253 (100\%) \\
\hline II-IV & $5(0 \%)$ & $2(0 \%)$ & $3(0 \%)$ & $2(0 \%)$ & $0(0 \%)$ & $3(0 \%)$ & $0(0 \%)$ \\
\hline \multicolumn{8}{|l|}{$\begin{array}{l}\text { Depression screening } \\
\text { and severity status }\end{array}$} \\
\hline $\begin{array}{l}\text { Screen-negative } \\
(\mathrm{PHQ}-2 \text { score }=0)\end{array}$ & 1,134 (55\%) & 602 (53\%) & $532(57 \%)$ & $237(52 \%)$ & 365 (54\%) & 361 (53\%) & $171(68 \%)$ \\
\hline $\begin{array}{l}\text { Minimal symptoms } \\
\text { (PHQ-9 score 1-4) }\end{array}$ & 349 (17\%) & $199(17 \%)$ & $150(16 \%)$ & $82(18 \%)$ & $118(18 \%)$ & $120(18 \%)$ & 30 (12\%) \\
\hline $\begin{array}{l}\text { Mild symptoms } \\
\text { (PHQ-9 score 5-9) }\end{array}$ & $370(18 \%)$ & $214(17 \%)$ & $156(17 \%)$ & 87 (19\%) & $128(19 \%)$ & $117(17 \%)$ & 39 (15\%) \\
\hline $\begin{array}{l}\text { Moderate symptoms } \\
\text { (PHQ-9 score } 10-19)\end{array}$ & $126(6 \%)$ & $71(6 \%)$ & $55(6 \%)$ & $28(6 \%)$ & $43(6 \%)$ & $43(6 \%)$ & $12(5 \%)$ \\
\hline $\begin{array}{l}\text { Severe symptoms } \\
\text { (PHQ-9 score } 20-27 \text { ) }\end{array}$ & $5(0 \%)$ & $5(0 \%)$ & $0(0 \%)$ & $1(0 \%)$ & $4(1 \%)$ & $(0 \%)$ & $(0 \%)$ \\
\hline Not assessed & 83 & 40 & 43 & 25 & 15 & 42 & 1 \\
\hline \multicolumn{8}{|l|}{ Suicidal thoughts } \\
\hline No thoughts & $1,876(95 \%)$ & 1,026 (94\%) & 850 (95\%) & 418 (96\%) & 608 (93\%) & 605 (94\%) & $245(97 \%)$ \\
\hline Passive thoughts & $56(3 \%)$ & $35(3 \%)$ & $21(2 \%)$ & $9(2 \%)$ & $26(4 \%)$ & $18(3 \%)$ & $3(1 \%)$ \\
\hline Active thoughts & $46(2 \%)$ & $27(2 \%)$ & $19(2 \%)$ & $7(2 \%)$ & $20(3 \%)$ & $18(3 \%)$ & $1(0 \%)$ \\
\hline Not assessed & $6(0 \%)$ & $3(0 \%)$ & $3(0 \%)$ & $1(0 \%)$ & $2(0 \%)$ & $0(0 \%)$ & $3(1 \%)$ \\
\hline
\end{tabular}

28 - Integrating depression management into HIV care in Lilongwe, Malawi: Feasibility and impact 
Baseline depression treatment plan, by clinic and period

\begin{tabular}{|c|c|c|c|c|c|c|c|}
\hline & \multirow{2}{*}{$\begin{array}{c}\text { Overall } \\
n(\%)\end{array}$} & \multirow{2}{*}{$\begin{array}{c}\text { Screening } \\
\text { phase } \\
n(\%)\end{array}$} & \multirow{2}{*}{$\begin{array}{c}\text { Active phase } \\
n(\%)\end{array}$} & \multicolumn{2}{|c|}{ Screening phase } & \multicolumn{2}{|c|}{ Active phase } \\
\hline & & & & $\begin{array}{c}\text { Clinic A } \\
\text { n (\%) }\end{array}$ & $\begin{array}{c}\text { Clinic B } \\
\text { n (\%) }\end{array}$ & $\begin{array}{c}\text { Clinic A } \\
\text { n (\%) }\end{array}$ & $\begin{array}{c}\text { Clinic B } \\
\text { n (\%) }\end{array}$ \\
\hline \multicolumn{8}{|l|}{$\begin{array}{l}\text { Mild depressive } \\
\text { symptoms (PHQ-9 } \\
\text { score 5-9)* }\end{array}$} \\
\hline Clinician counseling & $206(56 \%)$ & $191(89 \%)$ & 15 (10\%) & 77 (89\%) & $114(90 \%)$ & 11 (9\%) & $4(10 \%)$ \\
\hline FB counseling & $134(36 \%)$ & $0(0 \%)$ & $134(86 \%)$ & $0(0 \%)$ & $0(0 \%)$ & $103(88 \%)$ & 31 (79\%) \\
\hline$A D$ & $1(0 \%)$ & $1(0 \%)$ & $0(0 \%)$ & $0(0 \%)$ & $1(1 \%)$ & $0(0 \%)$ & $0(0 \%)$ \\
\hline $\begin{array}{l}\text { AD \& clinician } \\
\text { counseling }\end{array}$ & $1(0 \%)$ & $1(0 \%)$ & $0(0 \%)$ & $0(0 \%)$ & $1(1 \%)$ & $0(0 \%)$ & $0(0 \%)$ \\
\hline AD \& FB counseling & $2(1 \%)$ & $0(0 \%)$ & $2(1 \%)$ & $0(0 \%)$ & $0(0 \%)$ & $2(2 \%)$ & $0(0 \%)$ \\
\hline None* & $26(7 \%)$ & $21(10 \%)$ & $5(3 \%)$ & $10(11 \%)$ & $11(9 \%)$ & $1(1 \%)$ & $4(10 \%)$ \\
\hline \multicolumn{8}{|l|}{$\begin{array}{l}\text { Moderate depressive } \\
\text { symptoms (PHQ-9 } \\
\text { score } \geq 10 \text { ) }\end{array}$} \\
\hline Clinician counseling & 62 (47\%) & 60 (79\%) & $2(4 \%)$ & $18(62 \%)$ & 42 (89\%) & $1(2 \%)$ & $1(8 \%)$ \\
\hline FB counseling & $0(0 \%)$ & $0(0 \%)$ & $0(0 \%)$ & $0(0 \%)$ & $0(0 \%)$ & $0(0 \%)$ & $0(0 \%)$ \\
\hline$A D$ & $48(37 \%)$ & $7(9 \%)$ & $41(75 \%)$ & $5(17 \%)$ & $2(4 \%)$ & 37 (86\%) & $4(33 \%)$ \\
\hline $\begin{array}{l}\text { AD \& clinician } \\
\text { counseling }\end{array}$ & 15 (11\%) & $7(9 \%)$ & $8(15 \%)$ & $5(17 \%)$ & $2(4 \%)$ & $3(7 \%)$ & $5(42 \%)$ \\
\hline AD \& FB counseling & $4(3 \%)$ & $0(0 \%)$ & $4(7 \%)$ & $0(0 \%)$ & $0(0 \%)$ & $2(5 \%)$ & $2(17 \%)$ \\
\hline None & $2(2 \%)$ & 2 (3\%) & $0(0 \%)$ & $1(3 \%)$ & $1(2 \%)$ & $0(0 \%)$ & $0(0 \%)$ \\
\hline
\end{tabular}

*Those with missing baseline treatment plan $(n=4)$ treated as none; $A D=$ antidepressants, $F B=$ Friendship Bench 
Provision of depression treatment over first 6 months on ART during active phase

\begin{tabular}{|c|c|c|c|c|c|c|c|}
\hline & \multicolumn{7}{|c|}{ Window (Day since ART initiation) } \\
\hline & 0 & $1-45$ & $46-76$ & $77-106$ & $107-137$ & $138-167$ & $168-197$ \\
\hline \multicolumn{8}{|l|}{ Of those directed to FB: } \\
\hline $\begin{array}{l}\text { HIV appointment attended \& } \\
\text { FB session attended }\end{array}$ & 130 (93\%) & $62(44 \%)$ & $50(36 \%)$ & $46(33 \%)$ & $31(22 \%)$ & $9(6 \%)$ & $11(8 \%)$ \\
\hline $\begin{array}{l}\text { HIV appointment attended; } \\
\text { completed } 6 \text { FB sessions }\end{array}$ & $0(0 \%)$ & $0(0 \%)$ & $0(0 \%)$ & $0(0 \%)$ & $0(0 \%)$ & $10(7 \%)$ & $12(9 \%)$ \\
\hline $\begin{array}{l}\text { HIV appointment attended } \\
\text { but no FB session }\end{array}$ & $10(7 \%)$ & $40(29 \%)$ & 44 (31\%) & $38(27 \%)$ & $36(26 \%)$ & $36(26 \%)$ & $29(21 \%)$ \\
\hline Did not come to clinic & $0(0 \%)$ & $37(26 \%)$ & $43(31 \%)$ & 49 (35\%) & $60(43 \%)$ & 69 (49\%) & $70(50 \%)$ \\
\hline Transferred out & $0(0 \%)$ & $1(1 \%)$ & $3(2 \%)$ & $7(5 \%)$ & $13(9 \%)$ & $16(11 \%)$ & $18(13 \%)$ \\
\hline \multicolumn{8}{|l|}{$\begin{array}{l}\text { Of those prescribed } \\
\text { antidepressants:* }\end{array}$} \\
\hline $\begin{array}{l}\text { PHQ-9 assessed; AD } \\
\text { provided }\end{array}$ & 55 (100\%) & $20(36 \%)$ & $10(18 \%)$ & $12(22 \%)$ & $13(24 \%)$ & $8(15 \%)$ & $4(7 \%)$ \\
\hline $\begin{array}{l}\text { PHQ-9 assessed; no AD } \\
\text { provided }\end{array}$ & $0(0 \%)$ & $5(9 \%)$ & $8(15 \%)$ & $6(11 \%)$ & $3(5 \%)$ & $1(2 \%)$ & $1(2 \%)$ \\
\hline $\begin{array}{l}\text { No PHQ-9 assessed; no AD } \\
\text { provided }\end{array}$ & $0(0 \%)$ & $18(33 \%)$ & $15(27 \%)$ & $15(27 \%)$ & $11(20 \%)$ & $13(24 \%)$ & 17 (31\%) \\
\hline Did not come to clinic & $0(0 \%)$ & $11(20 \%)$ & $20(36 \%)$ & $20(36 \%)$ & $25(45 \%)$ & $29(53 \%)$ & $29(53 \%)$ \\
\hline Transferred out & $0(0 \%)$ & $1(2 \%)$ & $2(4 \%)$ & $2(4 \%)$ & $3(5 \%)$ & $4(7 \%)$ & $4(7 \%)$ \\
\hline
\end{tabular}

*antidepressants include either $\mathrm{AD}$ and $\mathrm{AD}$ and $\mathrm{FB} ; \mathrm{AD}=$ antidepressants; $\mathrm{FB}=$ Friendship Bench 


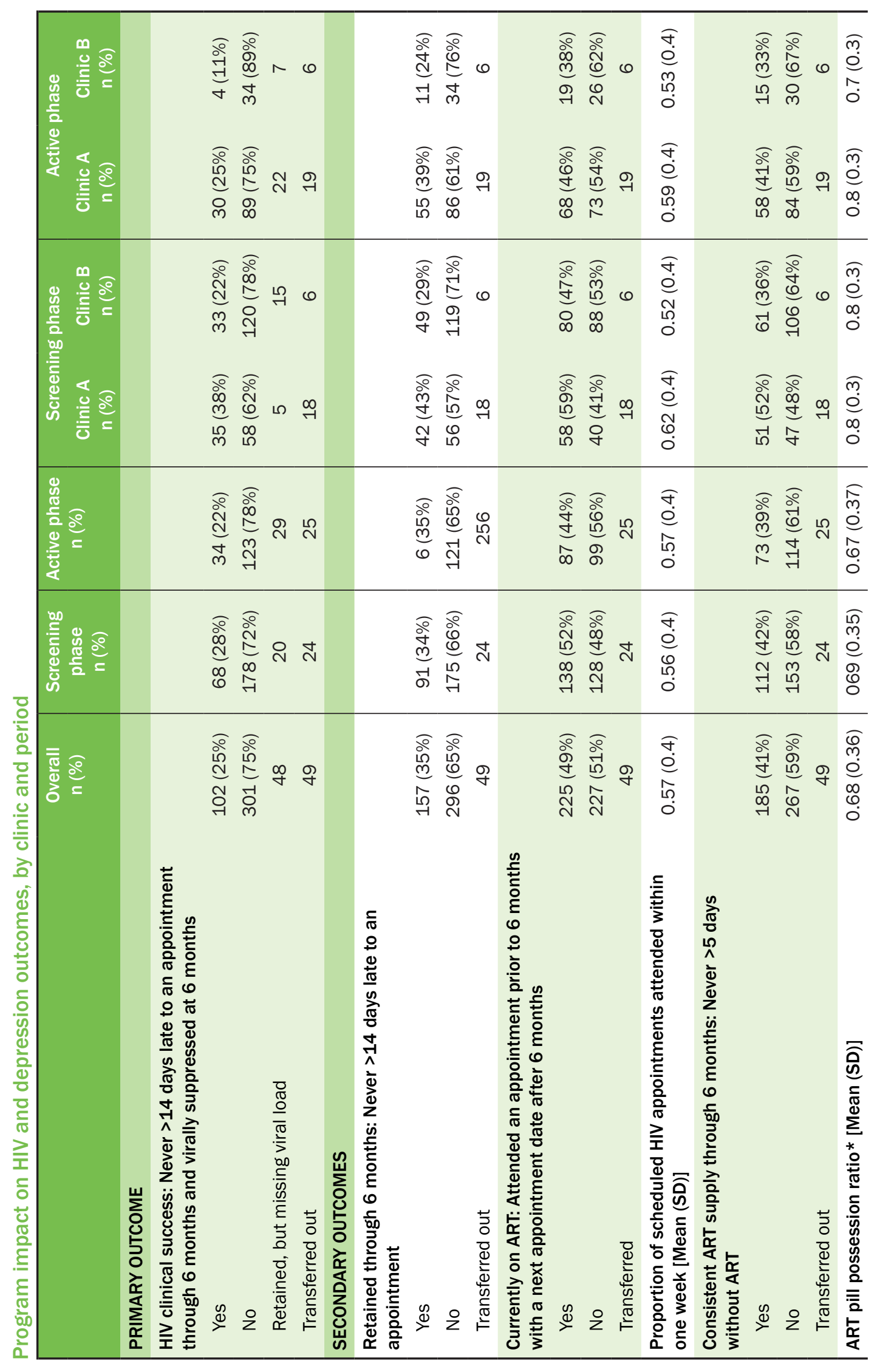




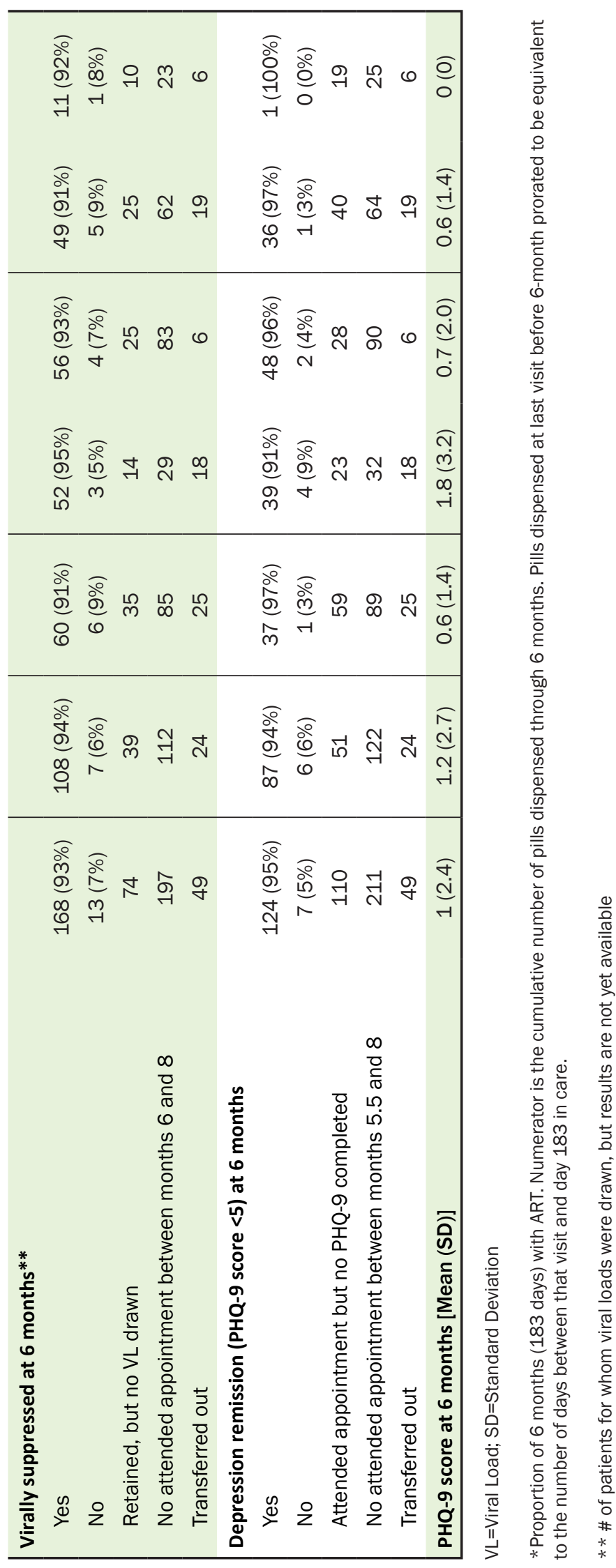


Of those who were directed to receive Friendship Bench counseling, 93 percent started Friendship Bench counseling the same day they initiated ART (Figure 5). During the first followup visit window (between days 1 and 45), only 44 percent of these patients also attended a Friendship Bench session. By the 6-month window (between days 168 and 197), only 8 percent of these patients also attend a Friendship Bench session and only 9 percent attended an ART appointment and had attended six Friendship Bench sessions prior to the start of this window. Over the course of the first six months of care, an increasing proportion of patients did not come to the clinic; by the 6-month window half of patients did not attend an appointment.

\section{Figure 5 Provision of depression treatment over first 6 months on ART during the active phase among those directed to receive Friendship Bench counseling $(\mathrm{N}=140)$}

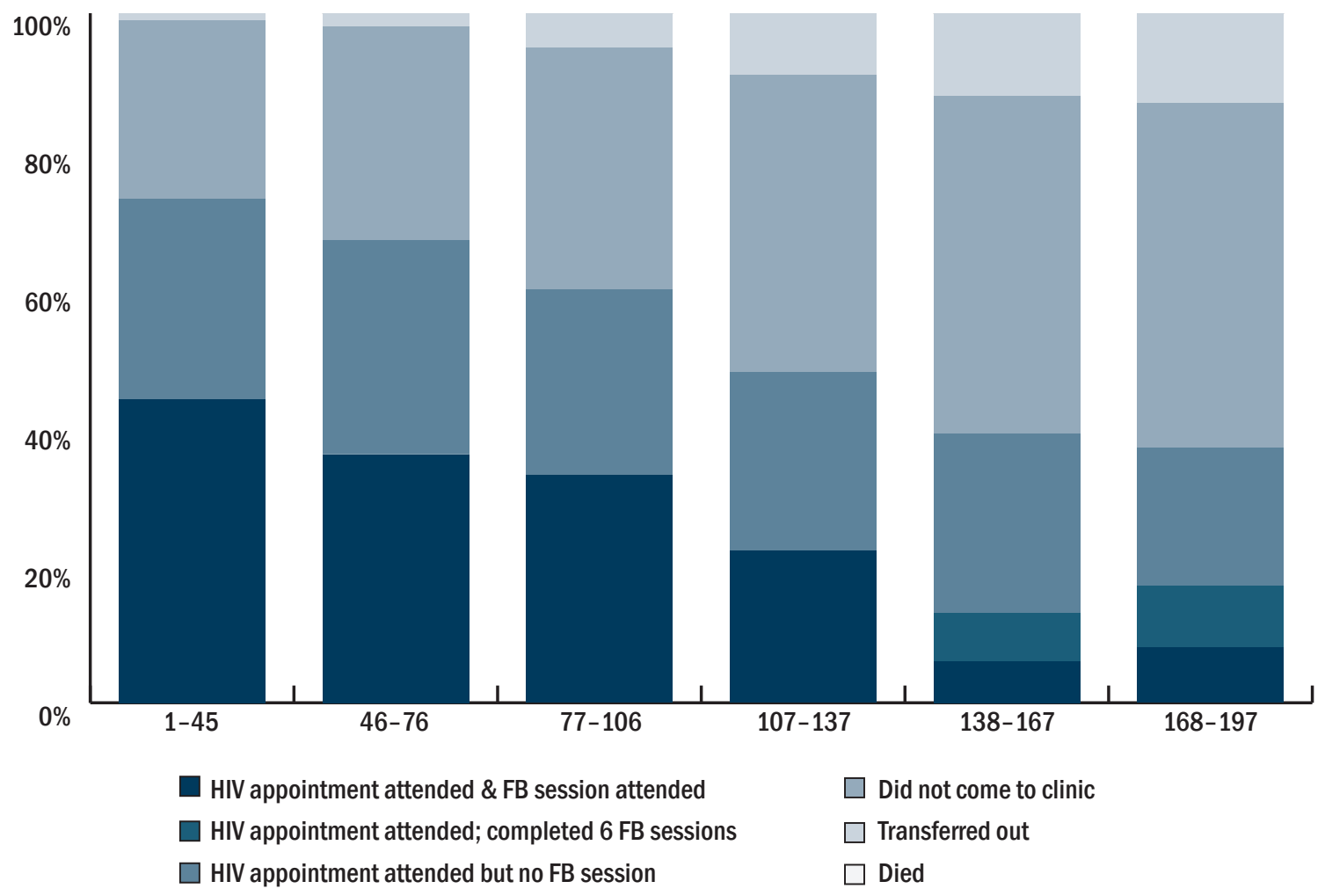

FB=Friendship Bench

Of the patients prescribed antidepressants, one-third received a second prescription of antidepressants at their first follow-up visit. By the 6-month window (between days 168 and 197), only 7 percent of patients attended an appointment and received antidepressants (Figure 6). During every follow-up window, between 20 percent and 33 percent of patients attended an appointment, but were not reassessed with the PHQ-9 and thus did not receive antidepressants. Similar to the patients who were referred for Friendship Bench counseling, patients who started antidepressants increasingly did not come to the clinic; by the 6-month window over half of patients did not attend an appointment. 
Figure 6 Provision of depression treatment over first 6 months on ART during the active phase among those prescribed antidepressants $(\mathrm{N}=55)$

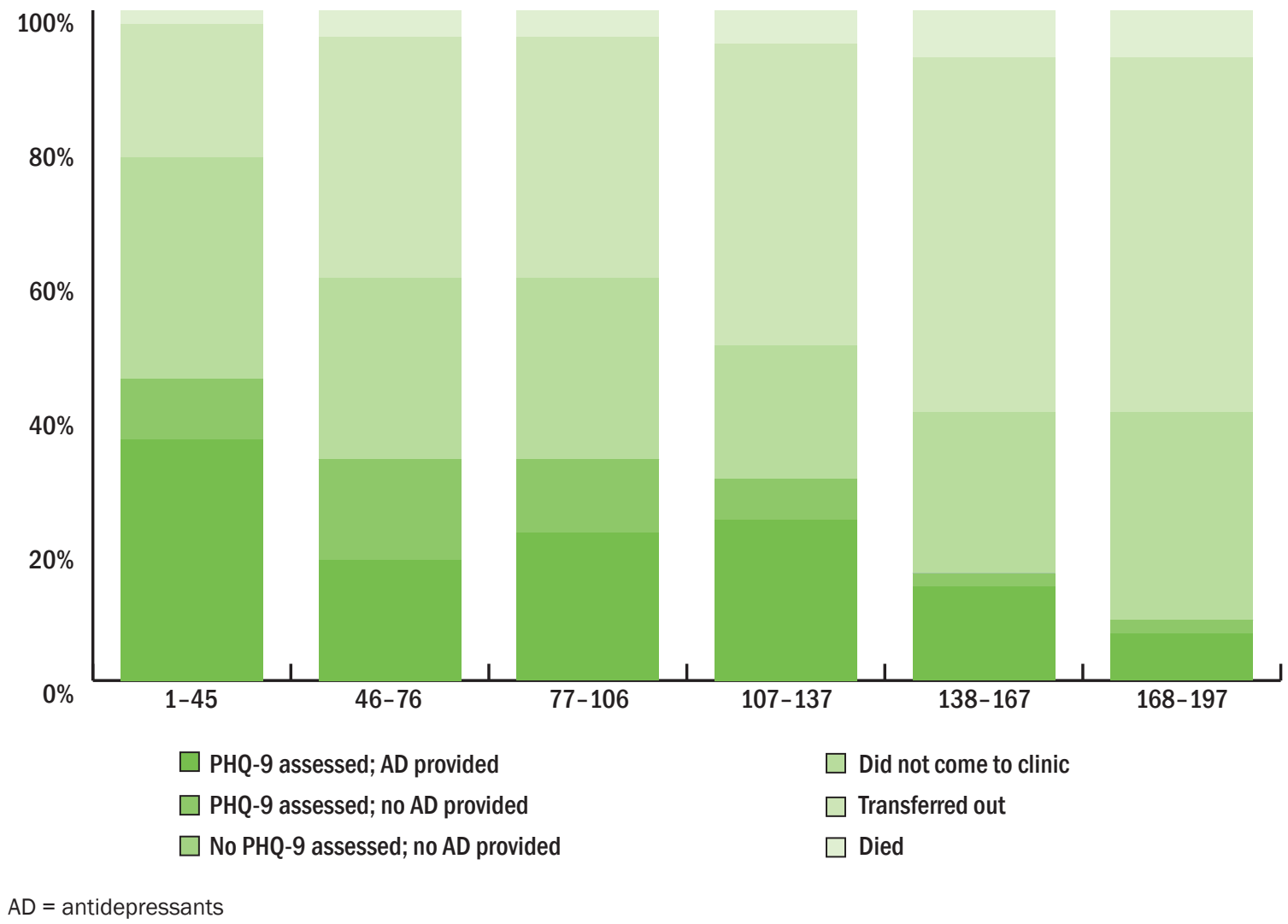


Integrating depression management into HIV care in Lilongwe, Malawi: Feaslbility and impact a 35 
Project SOAR

Population Council 4301 Connecticut Ave, NW,

Suite 280

Washington, D.C. 20008 USA

Tel: +1 2022379400

Fax: +1 2022378410

Ideas. Evidence. Impact.

projsoar.org 